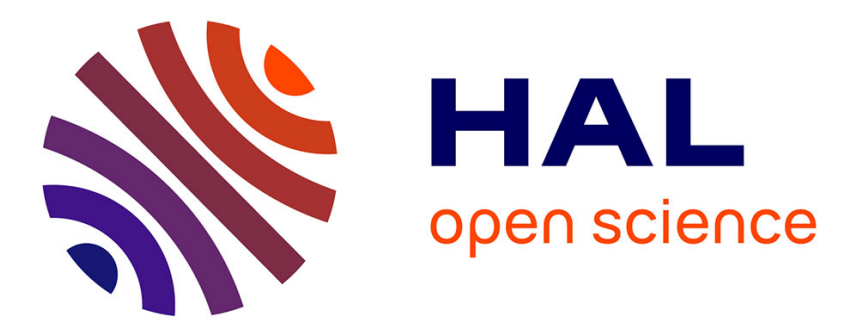

\title{
Low climate stabilisation under diverse growth and convergence scenarios
}

\author{
Anil Markandaya, Mikel Gonzalez-Eguino, Patrick Criqui, Silvana Mima
}

\section{To cite this version:}

Anil Markandaya, Mikel Gonzalez-Eguino, Patrick Criqui, Silvana Mima. Low climate stabilisation under diverse growth and convergence scenarios. Energy Policy, 2014, 64, pp.288-301. 10.1016/j.enpol.2013.07.046 . halshs-00872630

\section{HAL Id: halshs-00872630 https://shs.hal.science/halshs-00872630}

Submitted on 15 Oct 2013

HAL is a multi-disciplinary open access archive for the deposit and dissemination of scientific research documents, whether they are published or not. The documents may come from teaching and research institutions in France or abroad, or from public or private research centers.
L'archive ouverte pluridisciplinaire HAL, est destinée au dépôt et à la diffusion de documents scientifiques de niveau recherche, publiés ou non, émanant des établissements d'enseignement et de recherche français ou étrangers, des laboratoires publics ou privés. 


\title{
LOW CLIMATE STABILISATION UNDER DIVERSE GROWTH AND CONVERGENCE SCENARIOS
}

\author{
P. Criqui, M. González-Eguino, A. Markandya, S. Mima
}

April 2012

\begin{abstract}
In the last decade, a few papers have analysed the consequences of achieving the greenhouse gas concentration levels necessary to maintain global temperature increases below 2 degrees Celsius above preindustrial levels. Most models and scenarios assume that future trends in global GDP will be similar to the growth experienced in the past century, which would imply multiplying current output nineteen-fold in this century. However, natural resource and environmental constraints suggest that future global economic growth may not be so high. Furthermore, the environmental implications of such growth depend on how it is distributed across countries. This paper studies the implications on GHG abatement policies of different assumptions on global GDP growth and convergence levels in living standards between countries. A partial equilibrium model (POLES) of the world's energy system is used to provide detailed projections up to 2050 for the different regions of the world. The results suggest that while low stabilisation is technically feasible and economically viable for the world in all the scenarios considered, it is more likely to occur with more modest global growth. Convergence in living standards on the other hand places greater pressures in terms of the required reduction in emissions. In general we find that there are major differences between regions in terms of the size and the timing of mitigation costs and economic impact.
\end{abstract}

Key words: Climate policy, Economic growth, Convergence, Energy forecasting, Abatement cost, Partial Equilibrium models, Energy systems

JEL Classification: O44, Q4, Q47, Q54, C60 


\section{INTRODUCTION}

The objective of stabilising climate "at a level that would prevent dangerous anthropogenic interference with the climate system" (UNFCC 1992) means that global temperatures should not rise more than $2^{\circ} \mathrm{C}$ above pre-industrial levels, as stated by the United Nations in the Cancun Accords (UN 2010). According to the Intergovernmental Panel on Climate Change (IPCC 2007), this objective will require greenhouse gas concentrations to be limited to 400-450 ppm CO2-equivalent, and for that to happen global GHG emissions will need to peak in 2020 and be reduced by around $50 \%$ by 2050 (compared to 2000) and more than $80 \%$ by 2100 . Meeting low climate stabilisation targets requires considerable emission reductions in high-income countries, but also early involvement of developing countries.

In the past decade, a few papers have analysed the technical feasibility and the implications for the energy system and the economy of attaining low climate stabilisation levels. In the IPCC Fourth Assessment Report (IPCC 2007) several scenarios provide results for 400-450 ppm CO2eq., and a wide range of costs is reported. More recently, Edenhofer et al. (2010) provide a model comparison of low mitigation strategies. Using five ${ }^{1}$ different global models they find that low stabilisation levels are technically achievable and economically viable. Global mitigation costs, expressed as annual GDP losses, are reported to be between 1.5 and 3.5 per cent in 2050 for a 400 ppm scenario path ${ }^{2}$. Other studies (such as Nordhaus (2009)), which analyze more stringent targets $\left(1.5^{\circ} \mathrm{C}\right)$ ) report much higher costs as emissions need to peak earlier, when better technologies are not fully developed yet. There are also some models that report infeasibilities in achieving low stabilisation targets (Tol 2009).

Most of the models and scenarios currently in use assume that in next century the pattern of growth will be quite similar to that of the last century. According to Maddison (2001) global GDP increased 19-fold between 1900 and 2001, which means an annual GDP per capita compound growth rate of $1.9 \%$ (notice that if the period 1950-2001 is considered, the growth rate drops to $1.5 \%$ ). IPCC future scenarios show a wide range of GDP projections in their story

\footnotetext{
${ }^{1}$ These models are MERGE, REMIND, POLES, TIME, E3MG.

2 In all the models large amounts of biomass together with carbon sequestration are needed as emissions in 2100 must be negative to attain the $2^{\circ} \mathrm{C}$ stabilisation target given an intermediate population stabilisation of around 9.5 billion people. The annual losses increase in all four models during the transition phase of the energy system and decline thereafter. By 2100 losses of GDP range from about $0.9 \%$ to $2.5 \%$ relative to the baseline in the 400 ppm scenario compared to a range of 0.5 to $0.9 \%$ in the $550 \mathrm{ppm}$ scenario.
} 
lines. Although there have been successive reductions in the estimates ${ }^{3}$ the $50^{\text {th }}$ percentile of the distribution of GDP increase is between a factor of 7 and 14 (see IPCC 2007b, Riahi et al 2007). If differences in population projections are considered, the projected increase in GDP per capita is in the range of $2 \%$ per annum. These projections are also quite similar to the baseline scenarios of other well-known models, such as MIT-EPPA (Paltsev et al 2005), DICE (Nordhaus 2007) and WITCH (Bosetti et al 2009) $)^{4}$.

The spectacular increase in GDP in the last 100 years shows that during that period technological innovation and capital investment overcame the law of diminishing returns. Natural resources did not become a limiting factor in production. Industrial output increased by a factor of 40 , energy consumption by a factor of 16 , carbon and sulphur emissions by a factor of 10 and other items such as fish harvesting by a factor of 35 . Historical trends in the prices of marketed natural resources such as grains, energy and timber rose more slowly than the general price level (Johnson, 2000). However, this may not hold in the future with the anticipated increase in population and considering the implications for future key resource demands and environmental impacts. If specific resources and services are considered, such as fresh water and a wide variety of ecosystem services, there is evidence that growth projections, and probably even current utilization rates, are not sustainable (Vitousek et al 1997, Postel et al. 1996). Moreover, investment in human and manufacturing capital in many developing countries is not sufficient to offset the depletion of natural capital (Arrow et al 2001; World Bank, 2006).

Regarding convergence the differences between studies are much wider, reflecting differences on whether or not existing income gaps are viewed as gradually closing. For example in the IPCC SRES scenarios, developing countries gradually catch up at different speeds. The ratio ${ }^{5}$ of the average GDP per capita between industrialized countries and developing countries goes from 8.3 in 2000 to between 3 and 6.5 in 2050 and between 1.5 and 4 in 2100 . The highest rate of convergence in the IPCC SRES scenarios is similar to that experienced during the period 1950-

\footnotetext{
${ }^{3}$ The median of the post-SRES scenario is about $7 \%$ below the median of the SRES scenarios.

${ }^{4}$ In the baseline scenario selected in Edenhofer et al (2010) for multi model comparison GDP grows from 42 trillion (US\$ 2000) to around 400 by 2100 , a 10 -fold increase. The MIT-EPPA, DICE and WITCH models project GDP increases of 12.6, 11.2 and 8.3-fold respectively.

${ }^{5}$ The annual rate of income convergence between 11 world regions in the SRES (Special Report on Emissions Scenarios IPCC 2000) scenarios falls ranges from less than $0.5 \%$ in the A2 scenario family to less than $2 \%$ in A1 (in both PPP and MER metrics). B1 and B2 are intermediate scenarios in terms of convergence. The ratio between industrialised and developing countries in B1 and B2 is between 3.6 and 4 in 2050 and between 1.8 and 3 in 2100 .
} 
1990 in 90 regions $^{6}$ in Europe (Barro and Sala-i-Martin 1997). The rapid development and catchup scenarios remain in dispute as they imply higher productivity growth in the now developing countries than has been experienced in the past. There are also some models that diverge from these findings: for example in the MIT-EPPA model the ratio between developed and developing countries increases slightly. Although the projections in this model lead to per capita incomes by 2100 across all countries that for the most part are higher than US 2000 levels, the gap between some regions widens substantially. For example, the average GDP per capita in 2100 in the EU is projected to be $\$ 430,000$, whereas in Africa it is estimated at just $\$ 11,000,40$ times less, when the difference in 2000 is 13 times. Such inequalities may be socially unsustainable and may also be economically infeasible: there is empirical evidence for example that strong inequalities damage growth in the medium and long run (Persson and Tabellini 1994).

This article studies the implications of different global GDP growth levels together with different convergence levels between countries and regions in achieving low stabilisation targets. A global energy model (POLES) is used with a time horizon up to 2050 to analyse the implications of these paths and the consequences of introducing a climate policy (through carbon prices) to cut emissions by half by 2050 . Although the results are merely indicative of possible future trends given the high level of uncertainty inherent in such long run analyses - we believe they are helpful in understanding the long term implications for the energy and economic systems, especially in view of the long maturity periods entailed by investments in the energy sector.

The paper is organized as follows: Section 2 presents an overview of the model used; Section 3 describes the proposed baseline scenarios and the climate policy to be implemented; Section 4 analyses the energy and economic results for the different scenarios aimed at achieving low stabilisation. Section 5 offers some conclusions on the feasibility of low stabilization scenarios.

\footnotetext{
${ }^{6}$ Regions in Europe EU-15 defined at NUTS-1 level
} 


\section{THE MODEL}

The Prospective Outlook for Long-term Energy Systems (POLES) model $^{7}$ is a global sectoral simulation model for the development of long term energy supply and demand scenarios (EC 1996). The model allows the following to be carried out: i) projections of energy demand and supply by region/country with endogenous international oil/gas/coal prices; ii) simulations of technology development for electricity supply; iii) simulation of $\mathrm{CO} 2$ emissions; and iv) assessment of energy and climate policies.

The POLES model was developed in the framework of a hierarchical structure of interconnected sub-models at international, regional and national levels. Projections are made on the basis of exogenous economic growth and demographic projections for each region. Energy demand is deduced from economic variables (GDP, added values and private consumption) and energy prices through statistical ("econometric") relationships based on elasticities. The dynamics of the model is based on a recursive (year by year) simulation process of energy demand and supply with lagged adjustments to prices and a feedback loop through endogenous international energy prices. In the current version of the POLES model, the world is divided into 57 countries or regions, enabling the world regions that are of key importance for most energy studies to be identified. For each region, the POLES model implements four main modules dealing with: 1) final energy demand per main sector; 2) new and renewable energy technologies; 3) the conventional energy and electricity transformation system; and 4) the fossil fuel supply.

The POLES model includes more than 30 power generation technologies, including new/renewable technologies, and specific technologies/options such as renewables ${ }^{8}$, Carbon Capture and Storage (CCS) and hydrogen production. Technological choices and the energy mix are determined by capital and operating costs together with relative prices. The POLES model also contains endogenous learning curves that allow describing endogenously technology

\footnotetext{
${ }^{7}$ The POLES model has been developed by CNRS (France) since 1990. Currently it is operated, expanded and maintained by the CNRS/UPMF University, Enerdata and IPTS (Spain, European Commission research centre). ${ }^{8}$ Renewables can develop in the baseline scenario because of their cost efficiency in the long term. Wind energy is capped by its technical potential in relation to land availability (basically natural plains areas differentiated by wind speed classes with an excluding factor linked to the population density). For decentralised production, PV solar is constrained by the available surface area of buildings. The theoretical potential of thermodynamic solar power plants is linked to the size of sunny desert regions, but this vast potential is not usable for export because of the lack of transcontinental electricity grids and $\mathrm{H}_{2}$ transmission lines
} 
dynamics with learning rates and floor costs (minimum engineering cost). The energy mix typically changes slowly over time due to the long maturity of any investment in energy systems. The model covers 8 sectors of industry plus the agriculture, transport, residential and service sectors.

This model therefore provides a consistent framework for studying the dynamics of energy consumption and $\mathrm{CO} 2$ emissions worldwide. It takes into account the resource constraints for both oil and natural gas, and enables greenhouse gas emissions from burning fossil fuels to be calculated, along with the marginal cost of reducing emissions in the various countries or regions. It thus makes it possible to simulate various emission constraint scenarios and determine the consequences of introducing a carbon tax or emission constraints with trading systems. Like other sector and technology explicit economic models, its main advantage is in its detailed, robust estimation of the impacts of climate policies on the energy sector, but its main limitation is the absence of macro-economic feedbacks. The model does not cover all greenhouse gas emissions, notably those related to agriculture, land use, land-use change and forestry. As such, the climate component of the model does not allow for the projection of GHG stocks, concentrations and associated temperature rises from anthropogenic climate change.

The POLES model has been used in many forecasting studies, at both national and international levels, including those of the European Commission (EC 2003, 2007 ALSO INTRODUCE WETO-H2 STUDY'S REFERENCE) and the World Energy Council (WEC 2007). Most of its recent applications have involved studies assessing energy and climate policy issues (see e.g. Criqui et al 1999, Russ and Criqui 2007), but some have also been related to environmental implications (Markandya et al 2009). More detailed information on the POLES model can be found in Criqui (1996). Finally, a comparison of POLES models with other similar models can be found in Edenhofer et al (2010).

\section{THE SCENARIOS}

The scenarios for this project are based on two main factors: economic growth and convergence between countries. The former determines the level of world GDP growth and the latter the narrowing of the world's output distribution among regions/countries. The four possible 
scenarios considered are represented in Table 1, where "Medium Growth-HC" means medium economic growth and high convergence, "Low Growth-LC" means low economic growth and low convergence, and so on.

\section{[Table 1]}

Our approach to constructing the scenarios has been the following. World GDP is first determined using an exogenous annual world GDP per capita growth rate. Then the world GDP obtained each year is distributed among regions/countries using the ratios implicitly assumed by SRES scenarios A1 and B2 (IPCC 2001, Grubler et al 2007), which show low and high levels of convergence but with medium-high growth for Asia (Blanford et al 2008). In our scenarios we consider "medium growth" to mean an average world GDP per capita growth rate of $2 \%$ and "low growth" to mean $1.5 \%$. The population is the same for all the scenarios and is based on intermediate UN estimations (UN 2006).

[Table 2]

[Figure A]

The result obtained following this approach can be found in Table 2 (and also in figure A). The table shows the GDP per capita for different regions/countries and the four scenarios in 2000 and 2050. It also includes a column that gives the annual average growth rates. World GDP per capita increases from US\$7,430 in 2000 to US\$19,144 in 2050 for the Medium Growth scenarios $^{9}$ and to US\$15,316 for Low Growth scenarios. Within each scenario we consider different distributions of GDP growth in countries. For example in the Medium Growth-HC scenario, where high convergence levels are considered, we assume that the average GDP per capita of developing countries increases at a rate of 3.5\% whereas in the Medium Growth-LC it increases at $3.2 \%$. As the GDP growth level for the world is fixed, more growth in the developing countries corresponds to less growth in the developed countries. Therefore, developed countries have to grow at an average rate of $1 \%$ instead of $1.6 \%$. As most of the population and population increase will come from developing countries a small increase in their

\footnotetext{
${ }^{9}$ From here on, Medium Growth scenarios refer to Medium Growth-HC and Medium Growth-LC, independently of the convergence dimension. Conversely, High Convergence scenarios refer to Medium Growth-HC and Low Growth-HC. The same goes for Low Growth scenarios and Low Convergence scenarios.
} 
GDP per capita means a big decrease for developed ones. A rise from US\$12,715 to 14,735 in developing countries (15\%) means a drop in developed countries from US\$59,683 to 46,418 $(28 \%)$.

The Medium Growth-LC scenario is a standard scenario which is very similar to the baseline scenario adopted for example in Edenhofer et al (2010). The scenario that differs most from what is commonly found in the relevant literature is Low Growth-HC: in a world where growth is low but convergence is high, the GDP per capita growth rate in the developed countries has to be very low at around $0.6 \%$. Low levels of GDP growth, when GDP falls relative to its potential, have been associated in the past with increasing unemployment and instability. However, GDP per capita increases for all countries and in all the scenarios. Arguably, this scenario could be considered as the one most consistent with the view that future growth is likely to be environmentally constrained, while a higher degree of convergence will be necessary from a social and political perspective.

The four scenarios presented above give us the inputs (population and GDP values) required for the POLES model to obtain results in the baseline and "with climate policy" scenarios. The effect of climate policy will be evaluated against this baseline scenario, where it is assumed that climate policy has no decisive influence on the economy and the social sphere.

\subsection{Baseline Scenarios}

The baseline provides a description of the future world energy system under the different scenarios for growth and convergence. This baseline is developed in a "business and technical change as usual'" context, and no policies to reduce greenhouse gas emissions are included. The scenario serves as a benchmark for the assessment of alternatives, particularly with respect to resources, technologies and environmental/climate policy.

Figure 1 shows the inputs and results obtained from POLES model for the different baseline scenarios and for the world. The population is fixed in all the scenarios and reaches 9,128 million people in 2050, with most of the growth coming from the developing countries (China, India and Africa account for 1,392, 1,593 and 2,400 million people, respectively for that year). The world GDP increases from 53 trillion (2005 US\$ PPP) to 140 trillion in the Low Growth scenarios and 
to 175 trillion in the Medium growth scenarios. Conversely, the ratio of GDP per capita between developed and developing decreases from 7.3 in 2000 to 3.1 in the High Convergence scenarios, and to 4.6 in the Low Convergence scenarios.

[Figure 1]

World primary energy consumption increases from $417 \mathrm{EJ}^{10} /$ year in 2000 to between 760 and $880 \mathrm{EJ} /$ year in 2050. Energy consumption clearly increases with economic growth but also depends on the distribution of output. For the same global output, high convergence means more energy consumption, mainly because demand saturation effects are stronger in developed regions, while developing countries use less energy-efficient technologies so their economies are more energy-intensive.

World $\mathrm{CO} 2$ emissions increase from $24.2 \mathrm{GtCO} 2$ in 2000 to between 42.2 and $49.6 \mathrm{GtCO} 2$ in $2050^{11}$. Emissions clearly increase with economic growth and energy consumption. As oil and gas prices increase, coal consumption increases even more. High convergence also means more emissions, as developing countries' economies are more carbon-intensive. The difference in emissions in 2050 for the different growth levels is around $5 \mathrm{GtCO} /$ year for the high convergence case and $1.5 \mathrm{GtCO} 2 /$ year for the low convergence case. Although the impact of growth on emissions is clearly positive, the impact of convergence is not irrelevant. Moreover, the convergence assumption affects emission distributions, which have implications for mitigation.

Figure 2 shows the distribution of GDP and CO2 emissions in 2000 and 2050 for different scenarios. All the scenarios show a major decrease in the participation of the developed world in global output, from $63 \%$ in 2000 to around $32-42 \%$ in 2050 . The drop in the participation of the developed world in $\mathrm{CO} 2$ emission distribution is even greater, from 50\% in 2000 to less than $25 \%$ in all the scenarios in 2050 .

[Figure 2]

\footnotetext{
${ }^{10}$ Exajules

${ }^{11}$ The world emissions in 2050 for different scenarios are: Medium Growth-HC (49.6 GtCO2/year), Medium Growth-LC (47.9), Low Growth-HC (43.7), Low Growth-LC (42.2).
} 


\subsection{Scenarios with a low stabilisation target}

In this section we present the climate policy required to reduce $\mathrm{CO} 2$ emissions on a path consistent with the $2^{\circ} \mathrm{C}$ stabilisation target. For a low stabilisation path global $\mathrm{CO} 2$ emissions will need to peak around 2020 and then drop by around $50 \%$ by $2050^{12}$. However, meeting the low climate stabilisation target requires a distribution of emission reductions targets that, for reasons of fairness, should differ between developed countries -with high $\mathrm{CO} 2$ emissions per capita- and developing countries -with low $\mathrm{CO} 2$ emissions per capita-. The early involvement of developing countries is necessary for the target to be attained.

[Table 3]

Table 3 presents the emission reduction distribution targets we have adopted. Global emissions are supposed to increase by about $25 \%$ by 2020 (always compared to 2000 emissions) but will then decrease by $50 \%$ by 2050 . To that end different targets are considered for three different selected areas/regions: 1) the European Union (UE-27); 2) the Rest of Annex B ${ }^{13}$; and 3) NonAnnex B. The UE-27 has to reduce its emissions by $25 \%$ by 2020 and by $80 \%$ by 2050 . The reduction effort in the Rest of Annex B countries is delayed a little (in 2020 the reduction is $20 \%$ ), but they also go on to reduce their emissions by $80 \%$ by 2050 . Non Annex B emission reductions are determined as a residual -- once the reduction in the others is established -- to deliver the necessary global emission reduction. As a consequence, the Non-annex B countries can increase emissions by $73 \%$ by 2020 compared to 2000 (a reduction from their baseline emissions), but by 2050 they must reduce emissions by $10 \%$.

To implement these climate policy targets we use three different carbon values for each of the areas/“bubbles" considered. A bubble is an area within which a single marginal price for carbon abatement applies. Typically this means that there is either a harmonised carbon tax or a common market for emissions trading. In our case we introduce a carbon price that is increased to a level that reduces emissions to the desired level. The hypothesis behind this assumption is

\footnotetext{
${ }^{12}$ Emissions should be reduced by more than $80 \%$ by 2100 , but in this analysis the time horizon is 2050 .

${ }^{13}$ The group of countries included in Annex B in the Kyoto Protocol that have agreed to a target for their greenhouse gas emissions.
} 
that there will not be a unique carbon price (full trade regime) and global $\mathrm{CO} 2$ emission will not therefore be reduced at the theoretically least cost. However, we consider such a characterization more realistic. Furthermore this division allows the implications of different carbon values and mitigation costs associated with different levels of growth and convergence in different regions to be analysed.

\section{[Figure 3]}

Baseline emissions are different for each scenario and region and so, therefore, are mitigation efforts. Figure 3 shows world CO2 emissions for the different scenarios with carbon constraints. World baseline emissions in the Low Growth-LC scenario are the lowest so they can peak later and delay the reduction a little. By contrast, in the Medium Growth-HC reduction is brought forward so the final target is achievable. In all the scenarios emissions are reduced to the same level (12.1 GtCO2) by 2050.

\section{Results}

In this section the effects of a low stabilisation climate policy are assessed against the baseline for the four scenarios presented and their impacts on the future energy mix and mitigation costs are analysed. The energy mix and mitigation cost are functions principally of the POLES model's assumptions about the development of the consumption sectors, available technologies and learning rates, fossil resource prices.

\subsection{Future energy mix in the baseline on a low stabilisation path}

In a scenario with no climate policy, fossil fuels continue to dominate the energy system over the next 50 years in all four scenarios analysed, as the top left charts in Figures 4, 5, 6 and 7 show. Although the total primary energy consumption in each scenario is different, the storylines in the energy mix are very similar. Oil production increases ${ }^{14}$ slightly and then flattens out by 2050 . Gas production increases but reaches a peak in 2040 that cannot be surpassed. Although there is

\footnotetext{
${ }^{14}$ Conventional oil peaks at around $100 \mathrm{Mbd}$, which implies a strong increase in non-conventional oil production. The consistency of the long run oil projections of the POLES model is also based on the possibility of increasing recoverable resources through enhanced recovery rates.
} 
a noticeable development in nuclear energy, biomass and other renewables ${ }^{15}$ (in 2050 these non fossil energies represent around $20-25 \%$ of primary consumption), the source that gains most in importance is coal, which rises from $96 \mathrm{EJ}$ in 2000 to between 233 and290 EJ in 2050. The overall increase in coal is driven especially by increasing demand in Asia. This picture may vary from one country/region or scenario to another (for example in Europe renewable energy makes more progress whereas in China the penetration of coal is more significant, and high convergence drives increased coal consumption in developing countries) but fossil fuels and especially coal continue to dominate the energy mix.

[Figure 4]

[Table 4]

This energy mix pattern increases emissions greatly in all the scenarios. Indeed the change in global CO2 emissions in 2050 (\% of 2000 emissions) is between $+80 \%$ and $+87 \%$ in the Low Growth scenarios and between $+105 \%$ and $+112 \%$ in the Medium Growth scenarios. This increase would place all the scenarios except the Low Growth-LC in the very high range of the IPCC scenarios ${ }^{16}$, category VI, which means that global mean temperature would increase at equilibrium by between 4.9 and $6.1^{\circ} \mathrm{C}$ (see IPCC 2007, AR4 Table SPM.5).

[Figure 5]

[Table 5]

The first result of the analysis with climate policy is that in all the scenarios considered a low stabilisation target can be achieved. This is important because, as noted in the Introduction, not all models can reproduce such low emissions-stabilisation targets. However, a limitation of our result is that the analysis is constrained to 2050, so we cannot ensure feasibility beyond that time. In the mitigation scenarios, again, the energy mix paths for the different scenarios (see top right charts in Figures 4, 5, 6 and 7) are very similar. This is due to the strong constraint that is

\footnotetext{
${ }^{15}$ Renewables can develop in the baseline scenario because they are competitive in a number of places.

${ }^{16}$ According to post-TAR stabilisation scenarios a change in global emissions in 2050 ( $\%$ of 2000 emissions) of between +25 and +85 is associated with category $\mathrm{V}\left(5-6 \mathrm{~W} / \mathrm{m} 2\right.$ and temperature increase of $\left.4-4.9^{\circ} \mathrm{C}\right)$ and between +90 and +140 is associated with category VI $\left(6-7.5 \mathrm{~W} / \mathrm{m} 2\right.$ and temperature increase of 4.9-6.1 $\left.{ }^{\circ} \mathrm{C}\right)$.
} 
imposed on energy systems, although there are some differences in the magnitude of the carbonfree contributions to the energy mix and also in the timing of implementation of this technology.

The main storyline for the low stabilisation path is the following. First, the reduction of energy use plays an important role in the POLES model due to its detailed desegregation of demand-side energy efficiency improvements. Higher energy prices ${ }^{17}$ drive technological improvements that lead to energy savings in production but also changes in behaviour, in both residential uses and private transportation. Energy saving and efficiency measures reduce primary energy consumption by around 250-300 EJ in 2050 for all the scenarios, which accounts for around 25$30 \%$ of the energy consumption for that year in the baseline. Second, setting a price for CO2 dramatically reduces the contribution of fossil fuels, especially coal, to the energy mix. In the baseline scenario fossil fuels represent $75 \%$ of the total primary energy consumption in 2050 , with coal alone accounting for $35 \%$, and under the low stabilisation path that figure decreases to $50 \%$, with coal representing less than 20\%. Furthermore, in the stabilization scenarios most of the consumption in coal and gas-fired power plants in 2050 includes CCS units. Third, the portfolio of low-carbon technologies is supplemented with an increase in biomass, other renewables and nuclear. The increase in the installed power capacity of these technologies, as the bottom right charts in Figures 5,6,7 \& 8 show, is especially high in the case of renewables (around 13\% annual increase in 2000-2020 and 8\% in 2020-2050) as it is the case for biomass (around 8\% annual increase in 2000-2020 and $6 \%$ in 2020-2050). This storyline is made feasible by a major change in the power sector (where most of the emission reduction is attained) but also by reductions in the industrial and domestic sectors.

Tables 4, 5, 6 and 7 summarise the main indicators for different scenarios comparing the baseline and low stabilisation paths. Unless otherwise indicated, the results discussed below refer to the maximum range between the four scenarios in the year 2050 .

In the baseline scenario world energy demand is forecast to increase at 1.2-1.5\%/year from 2000 to 2050. The impact of economic and population growth is moderated by a decrease in energy intensity (of 1.1-1.2\%/year) due to the combined effects of structural changes in the economy,

\footnotetext{
${ }^{17}$ The price of oil varies between \$89/bl (2005US\$) in the Low Growth-LC scenario and \$104/bl in the Medium Growth-HC scenario for 2050.
} 
technological progress and energy price increases, even in the absence of a mitigation policy. In all the scenarios energy demand in developing countries grows rapidly, but especially so in the Medium Growth-HC scenario, where it increases at 2.5\%/year. Given the continued dominance of fossil fuels, world $\mathrm{CO} 2$ emissions in the baseline scenario increase at 1.2-1.5\%/year, and in developing countries at 3\%/year in the Medium Growth-HC scenario. Emissions per capita grow from $3 \mathrm{tCO}_{2}$ in 2000 to between 4.7 and $5.5 \mathrm{tCO}_{2}$ in 2050. In China and India emissions per capita increase considerably in the Medium Growth-HC scenario, from 2.4 and $0.9 \mathrm{tCO}_{2} / \mathrm{cap}$ in 2000 to 9.2 and $3.9 \mathrm{tCO}_{2} /$ cap respectively. In some developed countries per capita emissions decrease in all the scenarios due to population stabilisation and decreases in energy and carbon intensity. For example, in the US emissions per capita go from $20 \mathrm{tCO}_{2} /$ cap in 2000 to 15.1 and 12.8 in 2050 in the Low Convergence scenarios.

[Figure 6]

[Table 6]

If we compare the baseline scenario to the stabilisation pathway in 2050 , the effect of a carbon price is very clear (see last column in table 4, 5, 6, and 7). In the climate policy case, energy consumption per capita is reduced by around 33\% due to energy efficiency and energy saving measures, while electricity consumption per capita is reduced by only $15 \%$ due to carbon-free electricity replacing fossil fuel use. These reductions in energy and carbon intensity enable emissions per capita to be reduced by $71-75 \%$.

The main increase in electricity generation technologies comes from biomass $(+2483-3839 \mathrm{TWh}$; +232-292\%), solar (+2032-2492 TWh; +54-56\%) and nuclear (+1840-2429 TWh; +41.1-41.3\%). Comparisons with other technologies such as wind and hydro are not very remarkable as they break through even with no price set on carbon. These increases enable increasing electricity demand to be met with declining fossil fuel use, with a remarkable decrease in coal (60-63\%), oil (59.3\%-59.8) and gas-fired power plants (24-25\%).

Most production with fossil fuels includes the use of advanced coal and combined cycle plants, which enhance their thermal efficiency. However, the most relevant point is that most of this production includes the use of CCS. More than $80 \%$ of world production with coal in 2050 and 
more than 50\% with gas incorporates CCS units. Therefore, carbon sequestration starts increasing in 2020-2030 and by 2050 reaches between 7.1 and $7.8 \mathrm{GtCO}_{2}$ in Low Growth scenarios and between 8.9 and $9.3 \mathrm{GtCO}_{2}$ in Medium Growth scenarios. Since CCS is a non mature and "NIMBY syndrome exposed" technology, the implications of different scenarios are worth noting as higher growth and convergence imply, respectively, additional sequestration requirements of 1.5 and $0.5 \mathrm{GtCO}_{2}$ by 2050 .

[Figure 7]

[Table 7]

Finally, Figure 8 shows the impact of climate policy on installed capacity for the main powergenerating technologies in the different scenarios. Due to intermittency and low load factors, wind and solar are the technologies whose installed capacity increases most; together they add between $4300-5500 \mathrm{GW}$ by 2050, more than CCS, biomass and nuclear together. Wind power is installed in the first decades and then 3000-4000 GW of solar power are added. In the case of nuclear, capacity increases steadily from 2020 to 2050 and in the case of CCS, most of the growth occurs in 2030-2040. Finally, power from biomass increases especially in the last decade analysed. The penetration of the technologies clearly depends more on growth than on convergence, although there are increases in solar in the case of high convergence and medium growth. The only technology that shows relevant differences with convergence is CCS: the higher the convergence the higher the use of coal, particularly in Asia, and hence strong CCS development to comply with climate targets.

[Figure 8]

\subsection{Mitigation costs}

In general, four different types of mitigation costs can be distinguished: direct engineering costs, economic costs for a specific sector (abatement cost; Edenhofer 2010), macroeconomic costs and welfare costs. In the case of the POLES model, as GDP is prescribed exogenously the mitigation costs for the transition of the energy system are provided as the sum of the implied costs of demand reduction through price-effects and of the costs of changing the technology mix according to a merit order that reflects direct engineering costs. These costs are also reported as 
a proportion of GDP values to facilitate comparison between our results and those of other models and cost concepts.

\subsubsection{Carbon prices}

The carbon prices required for the reduction targets in each region to be attained are presented in Figure 9. The carbon price drives investments in energy efficiency and carbon-free technologies and rises over time in all the scenarios. The effects of convergence on carbon prices are shown very clearly.

In the case of EU-27 the resulting carbon prices (for a reduction of $25 \%$ in 2020 and $80 \%$ in 2050) increase rapidly to $\$ 100-160 / \mathrm{tCO}_{2}$ in 2020 , $\$ 250-380$ in 2030 and $\$ 485-655$ in 2050 . The highest carbon prices are obtained in the scenario where baseline emissions for developed countries are highest - the Medium Growth-LC scenario -. Conversely, the lowest carbon prices are found when developed countries have the lowest emissions - the Low Growth-HC scenario-. It is noteworthy that carbon prices are a little higher in the Low Growth-LC scenario than in the Medium Growth-HC scenario; this means that for the EU-27 the carbon price is affected more by convergence than by growth assumptions ${ }^{18}$.

In the Rest of Annex B countries the pattern is similar to that found in EU-27, but the carbon price is markedly lower, as there are more initial opportunities to be exploited in those countries and mitigation costs are thus lower. The resulting carbon prices (for a reduction of 20\% in 2020 and $80 \%$ in 2050) increase steadily from $\$ 41-56 / \mathrm{tCO}_{2}$ in 2020 to $\$ 136-172$ in 2030 and $\$ 406-477$ in 2050. Again there is not much difference in carbon prices between the Medium Growth-HC and Low Growth-LC scenarios.

[Figure 9]

Non Annex B countries have lower emission reduction targets ( $+73 \%$ by $2020,-10 \%$ by 2050$)$, but since their economic and energy consumption prospects are also high they still need to make

\footnotetext{
${ }^{18}$ To put these taxes in perspective a tax of US\$500 per ton of CO2 amount to an additional charge of US\$1.3 per liter for a vehicle that generates $2.6 \mathrm{~kg}$ per liter. The actual increase in the price of motor fuel compared to the baseline, however, will be less, as the price of crude oil is lower with the carbon tax than it is without the tax.
} 
a significant effort, as carbon prices show. The resulting carbon prices increase slowly to $\$ 0$ $18 / \mathrm{tCO}_{2}$ in 2020 and $\$ 13-73$ in 2030 , but then increase sharply to $\$ 222-285 / \mathrm{tCO}_{2}$ in 2050 . In this case, the highest carbon prices are obtained in the scenario where baseline emissions for developing countries are highest - the Medium Growth-HC scenario - and lower where emissions are lowest - the Low Growth-LC scenario. At any time, the price for each scenario in EU-27 is more than twice as high as in the Non-Annex B countries and 1.5 times that in the Rest of Annex B countries..

\subsubsection{Worldwide mitigation costs}

Once the carbon prices and the corresponding emission reductions have been obtained for each region abatement cost curves can be calculated. Total abatement costs are the areas under the abatement cost curves up to the target reduction for each country.

Figure 10 shows the mitigation cost for the world. The main result shown in this figure is that reducing $\mathrm{CO}_{2}$ emissions has a cost when compared to the option of emitting without constraints and without a carbon price. Moreover, the form of this function indicates that cost will increase as the level of reductions increases and the best abatement options (possible alternatives) are exhausted. Mitigation costs increase from 75-140 billion/year in 2020 up to 2777-3290 billion/year in 2050 .

In all the scenarios mitigation costs increase over time as reduction efforts increase. Mitigation costs in Medium Growth scenarios are higher than in Low Growth scenarios, as the effect of high convergence growth outweighs the effect of growth. The only exception to this trend can be found between 2000-2018, when Low Growth-LC mitigation costs are higher than those for Medium Growth-HC; in the early periods developed countries need to make more effort to control emissions and carbon prices in developing countries are very low.

Most of the time, mitigation costs are higher with high convergence levels. This is mainly because global emissions increase with higher convergence (see Figure 1 and Section 3). However, this pattern can change over time as higher convergence also means more emissions in the developing world, where mitigation costs (and carbon prices) are lower compared to 
developing countries. For example in 2020 mitigation costs are lower with high convergence because that means a far greater emission reduction effort from developing countries. Mitigation cost differences due to convergence disappear by 2030 and by 2040 costs are higher with high convergence levels. It is interesting to notice however that this trend is reversed again in the Medium Growth scenario when approaching 2050 because when the reduction effort in developed countries is very high (and as it is not possible to trade emission allowances between developed and developing countries) the carbon price also starts to be very high and mitigation increases more.

[Figure 10]

[Table 8]

These mitigation costs can also be reported as a percent of GDP (see table 8). Measured in these terms, the impact also increases over time. An important result of this paper is that low stabilisation targets can be achieved with a cost that is less than $2 \%$ of GDP in 2050 , which is just around a one year delay in global GDP growth over the period 2000 to 2050.

However, a look at the impacts relative to GDP for each scenario reveals some surprising results. Although mitigation costs increase with growth it is remarkable that the economic impact can work in the opposite direction, i.e. the economic impact is higher in the Low Growth scenarios in the later periods. The explanation for this is simple: the economic impact is calculated as the percentage of mitigation cost compared to global GDP in each scenario. As GDP growth is lower in Low Growth scenarios the proportion of the losses turn out to be higher. This happens during the later periods, when increases in mitigation costs outweigh economic growth.

\subsubsection{Regional mitigation costs and macroeconomic impact}

In this section the regional mitigation costs impacts relative to GDP are analysed. Figure 11 shows the mitigation costs for different major regions and different scenarios up to 2050. Most of the mitigation costs are supported by the developed world, especially the US (US\$610-685 
billion) and the UE-27 (US\$533-665 billion), though China also makes a major contribution (US\$407-592 billion).

[Figure 11]

The scenarios affect developing and developed countries in different ways in term of mitigation costs. On the one hand, in the developed world mitigation costs are higher with low convergence, as this means more reduction for them. Less growth normally means lower mitigation costs but this does not always hold because for example (see Table 2) in Europe the GDP per capita is higher in Low Growth-LC than in Medium Growth-HC, and that means more energy and emissions. On the other hand, in the developing world it is clearer that mitigation costs decrease with lower growth and lower convergence. Only in the case of China in Medium Growth-LC and Low Growth-HC are mitigation costs very similar because (see Table 2) its GDP per capita is very similar in both cases.

Finally, Figure 12 plots the impact as a percent of GDP for EU-27, US, China and India for each scenario between 2000 and 2050. As explained above, low growth can result in greater impact relative to GDP in the later periods when increases in mitigation costs outweigh economic growth. This effect is clearly shown in EU-27 and in the US in the Low Growth-HC scenario, where growth in the developed world is weaker and the impact is clearly much higher.

In the cases of China and India there is a clear difference in the timing of the impact depending on the scenario. The highest impact is, of course, in the Medium Growth-HC scenario and the lowest in the Low Growth-LC. In fact between 2030 and 2040, when these countries start reducing their emissions more intensively, the difference in the impacts of the two scenarios is great. In China in 2040, depending on the scenario, the impact may be $0.5 \%$ of GDP or $2 \%$ : this is a remarkable difference. The effects of growth and convergence together may not be so intense in developed countries but may result in remarkable differences in developing countries. This result should be taken into account when designing participatory regimes for countries that are growing very fast. 
[Figure 12]

\section{CONCLUding REMARKS}

This article studies the implications of GDP growth and convergence in living standards of different countries on achieving low climate stabilisation. A reduction in worldwide emissions of around $50 \%$ by 2050 is imposed (a path that will most likely keep global temperature change to below $2^{\circ} \mathrm{C}$ ). The reduction targets are distributed in such a way that developed countries reduce their emissions by $80 \%$ and developing countries by $10 \%$ by 2050 using different carbon prices in different areas. A global energy model (POLES) is used to analyse the implications of these scenarios on climate policies. Three main conclusions come out of this study: i. the low stabilization scenarios are technically feasible according to the POLES model; ii. the abatement cost in the energy sector in all cases represent only a limited fraction of GDP, less than 2\%; iii. the impacts differ across regions according to the scenarios, but in all cases the developed world support most of these costs.

In a "business and technical change as usual" scenario fossil fuels, especially coal, dominate and world CO2 emissions can be expected to double in 50 years (from 24 GtCO2 in 2000 to 42 50 GtCO2 in 2050, depending on the scenario). Emissions increase with growth and convergence: the difference in growth adds around $5 \mathrm{GtCO} /$ year while going from a low convergence to a higher convergence scenario adds $1.5 \mathrm{GtCO} 2 /$ year by 2050. Although the impact of growth is higher, the impact of convergence is not irrelevant and affects emission and mitigation cost distribution. This increase places all the scenarios except the low growth and low convergence scenario in IPCC category VI, which means that global mean temperature is expected to increase by between 4.9 and $6.1^{\circ} \mathrm{C}$.

If a climate policy is introduced, the analysis shows first that it is technically feasible to attain stabilisation consistent with a $2^{\circ} \mathrm{C}$ target. This is important as this result implies a full change in the "energy paradigm" and not all the modeling systems reproduce this change. Carbon prices reduce energy consumption per capita by around 33\% due to a higher energy efficiency, and electricity consumption per capita by only $15 \%$ due to the role of carbon-free electricity. This shows an "electrification" accompanying the "de-carbonisation" of the global energy system. 
The main increase in power capacity comes from solar, but biomass and nuclear also contribute significantly (see Section 4.3), as those sources break through even with no carbon price being set. Most of the production with fossil fuels includes CCS. High growth and convergence implies a need for a further 0.5 and $1.5 \mathrm{GtCO}_{2}$ of sequestration, respectively, by 2050 . This is important as higher convergence implies reliance on a more risky technology to achieve the $2^{\circ} \mathrm{C}$ target. In general, the penetration of the technologies clearly depends more on growth than on convergence but the energy mix storyline is very similar in all the scenarios.

Secondly, from the economic perspective the analysis show the viability of low stabilisation. The economic impact for the energy sector represents less than $2 \%$ of total GDP in 2050 for all the scenarios, even with high growth and high convergence. This impact can be seen as a one year delay in economic growth to attain low stabilisation. These results are within the range found in the relevant literature, which, according to the IPCC (2007, see Table SMP 6), could be up to $5.5 \%$ GDP reduction for least cost trajectories. The lower impact obtained in this analysis (though it is not least-cost based as there are three different carbon prices) can be explained on the one hand by the fact that, by construction of the exercise, macro-economic feedbacks are not taken into account by the model, and on the other hand by the fact that many options on the demand side regarding energy and efficiency measures (the cheapest options) are available in the POLES model.

Mitigation costs increase from US\$75-140 billion/year in 2020 to US\$2,777-3,290 billion/year in 2050, depending on the scenarios. The functional form of the mitigation cost curves shows that, proportionally, costs increase more as reductions increase and the best mitigation options are exhausted. The effect of high convergence is in general outweighed by the effect of growth. Although mitigation costs are higher with high convergence levels (global emissions are higher), this pattern can change as the emission reduction in the developed world tends to be more expensive, as mitigation cost curves show. At any time, the carbon price for each scenario in developed countries is more than twice that of developing ones. The carbon price in UE-27 (Annex B) increases by 2050 to $\$ 485-655 / \mathrm{tCO}_{2}$ while in the Non-Annex B area it increases to $\$ 222-285 / \mathrm{tCO}_{2}$. 
A look at the impacts for each scenario relative to GDP reveals surprising results. Although mitigation costs increase with growth, the economic impact is higher in the Low Growth scenarios. This occurs because, although the costs increase with GDP, they increase more slowly than the increase in GDP, resulting in a decline in the mitigation costs as a percent of GDP.

Thirdly, there are major differences in economic impact from one region/country to another depending on the growth and convergence assumptions. Most of the mitigation cost is supported by the developed world, especially the US (US\$610-685 billion) and the UE-27 (US\$533-665 billion), though China also makes a significant contribution (US\$407-592 billion). In the developed world, mitigation cost are higher with low convergence, and in the developing world the opposite is true. For example, in EU-27 and the US the impact is quite high (3-4\%) in the Low Growth-High Convergence scenario. The effect of growth and convergence may not be so intense in developed countries, but can be crucial in developing countries. In China, for example, depending on the scenario the impact in 2040 may be $0.5 \%$ of GDP or $2 \%$. The insights provided on the timing of the impact should be taken into account when designing participatory regimes for countries that have low emissions per capita but that are growing fast.

Overall, the results indicate that lower global growth in GDP does not make it particularly easier to achieve the stabilization target of $2^{\circ} \mathrm{C}$. To be sure, the cost of attaining the target goes up with global growth but it goes up less fast than the increase in GDP and so the percentage costs fall. The results also suggest that while high convergence of GDP across countries increases the cost of attaining the target in global terms, this increase is quite modest. High convergence does, however, imply a higher burden in absolute terms as well as relative to GDP in developing countries. In the developed world mitigation costs are higher with low convergence, although the difference between the different convergence scenarios is not as sharp as it is in the case of developing countries. Finally we note that the high convergence scenarios are more dependent on a large scale development of future technologies such as CCS to attain the stabilization goal.

To close we would like to make the important caveat that these results involve a high level of uncertainty and should be treated cautiously. Yet we believe the storyline behind our results should be helpful in understanding the implications for energy and economic systems when decisions are made regarding climate policies that need to look very far into the future. 


\section{REFERENCES}

Arrow, K. Dasgupta, P., Goulder, L. Daily, G. , Ehrlich, P, Heal, G. Levin, S. Mäler, K.G, Schneider, S., Starrett, D. , Walker, B. (2004), The Journal of Economic Perspectives, Vol. 18, No. pp. 147-172.

Barker, T. and Scrieciu, S. (2010). "Modeling Low Climate Stabilization with E3MG:Towards a 'New Economics' Approach to Simulating Energy-Environment-Economy System Dynamics", The Energy Journal, 31 (Special Issue): 137-164.

Blanford, Geoffrey J., Richard G. Richels, and Thomas F. Rutherford. "Revised Emissions Growth Projections for China: Why Post-Kyoto Climate Policy Must Look East." Discussion Paper 08-06, Cambridge, Mass.: Harvard Project on International Climate Agreements, September 2008.

Bossetti, V. Tavoni, E., Sgobbi, A. (2009) The 2008 WITCH Model: New Model Features and Baseline, FEEM Working Paper 85, Milan.Clarke, L., Edmonds, J., Krey, V., Richels, R., Rose, S., and Tavoni, M. (2009). International Climate Policy Architectures: Overview of the EMF 22 International Scenarios. Energy Economics, 31, 1, 64-81.

Criqui, P. (1996): "Prospective Outlook on Long-term Energy Systems", EUR 17358 EN, European Commission, Brussels.

Criqui, P., Mima, S., Viguier, L., 1999. Marginal abatement costs of CO2 emission reductions, geographical flexibility and concrete ceilings: an assessment using the POLES model, Energy Policy, 27 10, 585-601.

EC (1996) POLES 2.2, European Commission DG XII, EUR 17358 EN, 1996.

EC (2003): "World Energy, Technology, and Climate Policy Outlook: WETO 2030", EUR 20366, Directorate General for Research, European Commission, Brussels.

Edenhofer, O., Knopf, B., Barker, T., Baumstark, L., Bellevrat, E., Chateau, B., Criqui, P., Isaac, M., Kitous, A., Kypreos, S., Leimbach, M., Lessmann, K., Magne, B., Scrieciu, S., Turton, H. and van Vuuren, D. (2010). "The Economics of Low Stabilization: Model Comparison of Mitigation Strategies and Costs", The Energy Journal 31(Special Issue): 11-48.

Grübler, A., N. Nakicenovic, J. Alcamo, G. Davis, J. Fenhann, B. Hare, S. Mori, B. Pepper, H. Pitcher, K. Riahi, H.H. Rogner, E.L. La Rovere, A. Sankovski, M. Schlesinger, R.P. Shukla, R. Swart, N. Victor, and T.Y. Jung, 2004: Emissions scenarios: a final response. Energy and Environment, 15(1), pp. 11-24.

Grúbler, A., O'Neill, K. Riahi, V. Chirkov, A. Goujon, P. Kolp, I. Prommer, S. Scherbov, E. Slentoe (2007) Regional, national, and spatially explicit scenarios of demographic and economic change based on SRES, Technological Forecasting and Social Change, 74, 7, 980-1029.

Hamilton, J.D. (2009), Understanding Crude Oil Prices, Energy Journal 2009, 30, 2, 179-206

IPCC (2007) Climate Change 2007: Fourth Assessment Report AR4, Synthesis Report, Intergovernmental Panel on Climate Change, Cambridge, UK and New York, USA.

IPPC (2001), IPCC Special Report on Emissions Scenarios, Cambridge, UK and New York, USA. 
Johnson, D.G. (2000), Population, Food, and Knowledge, American Economic Review. 90:1, pp. $1-14$.

Maddison, A., 2001: The World Economy: A Millennial Perspective. OECD, Paris.

Markandya, A. Armstrong, B.G., Hales, S., Chiabai, A., Criqui, P., Mima, S., Tonne, C., Wilkinson, P (2009), Public health benefits of strategies to reduce greenhouse-gas emissions: low-carbon electricity generation, The Lancet, 374, 2006-2015.

Nordhaus, W. (2008) A Question of Balance. Yale University Press, New Haven \& London.

Paltsev, S. Reilly, JM, Jacoby, H.D. Eckaus, R.S, McFarland, J., Sarofim, M. Asadoorian M. and Babiker M (2005) The MIT Emissions Prediction and Policy Analysis (EPPA) Model: Version 4, WP 71, MIT Global Change Joint Program, Cambridge, MA.

Persson, T. Guido Tabellini G. (1994), Is Inequality Harmful for Growth? The American Economic Review , 84, 3. 600-621.

Postel, Sandra L., Gretchen C. Daily and Paul R. Ehrlich. 1996. "Human Appropriation of Renewable Fresh Water" Science, 9, 271, pp. 785-88.

Riahi,K. Grubler, A. Nakicenovic, N. (2007)Scenarios of long-term socio-economic and environmental development under climate stabilization, Technological Forecasting and Social Change, 74, 7, 887-935,

Russ, P. and P. Criqui (2007), Post-Kyoto CO2 emission reduction: the soft landing scenario analysed with POLES and other world models, Energy Policy, 35, 786-796.

Tol, R.S.J (2009) The Feasibility of Low Concentration Targets: An Application of FUND. Energy Economics, 31, 121-130.

United Nations, 2001: World Population Prospects: The 2000 Revision, Data in digital form.

van Vuuren, D. P., den Elzen, M. G. J., Lucas, P. L., Eickhout, B., Strengers, B., van Ruijven, B., Wonink, S., and van Houdt, R. (2007). "Stabilizing greenhouse gas concentrations at low levels: an assessment of reduction strategies and costs." Climatic Change, 81(2): 119-159.

Vitousek, P. M., H. A. Mooney, J. Lubchenco and J. M. Melillo. 1997. "Human Domination of Earth's Ecosystem." Science. July 26, 277, pp. 494-99.

WEC (2007), Deciding the Future: Energy Policy Scenarios to 2050, World Energy Council, London.

World Bank (2006), Where is the Wealth of Nations: Measuring Capital for the $21^{\text {st }}$ Century, World Bank, Washington DC. 


\section{FIGURES AND TABLES}

Table 1. Alternative scenarios

\begin{tabular}{|l|c|c|}
\hline & High Convergence & Low Convergence \\
\hline Medium Growth & Medium Growth-HC & Medium Growth-LC \\
\hline Low Growth & Low Growth-HC & Low Growth-LC \\
\hline
\end{tabular}

Note: Alternative scenarios are solved with the POLES model for the Baseline and with the climate policy necessary for a 2 degree stabilisation path. 
Table 2. GDP per capita (US\$ 2005 PPP) and annual average growth rates (2000-2050) for different scenarios by regions

\begin{tabular}{lr|rr|rr|rr|rr}
\hline & & Medium Growth-HC & Medium Growth-LC & \multicolumn{2}{|c}{ Low Growth-HC } & \multicolumn{2}{|c}{ Low Growth-LC } \\
& 2000 & 2050 & $(\%)$ & 2050 & $(\%)$ & 2050 & $(\%)$ & 2050 & $(\%)$ \\
\hline World & 7,430 & 19,144 & 2.0 & 19,144 & 2.0 & 15,316 & 1.5 & 15,316 & 1.5 \\
\hline Developed Countries & 27,865 & 46,418 & 1.0 & 59,683 & 1.6 & 37,136 & 0.6 & 47,749 & 1.1 \\
\hline United States & 38,746 & 56,514 & 0.8 & 69,475 & 1.2 & 45,213 & 0.3 & 55,582 & 0.7 \\
Europe & 24,042 & 40,554 & 1.1 & 54,315 & 1.7 & 32,444 & 0.6 & 43,454 & 1.2 \\
Japan & 28,564 & 46,804 & 1.0 & 60,067 & 1.5 & 37,445 & 0.6 & 48,055 & 1.1 \\
Rest of the rich countries & 29,869 & 45,473 & 0.9 & 56,379 & 1.3 & 36,380 & 0.4 & 45,105 & 0.8 \\
\hline Developing Countries & 2,750 & 14,735 & 3.5 & 12,715 & 3.2 & 11,789 & 3.0 & 10,173 & 2.7 \\
\hline India & 1,701 & 14,446 & 4.5 & 11,354 & 4.0 & 11,557 & 4.0 & 9,083 & 3.5 \\
China & 2,641 & 19,254 & 4.1 & 16,279 & 3.8 & 15,404 & 3.7 & 13,024 & 3.3 \\
Africa & 2,330 & 9,314 & 2.9 & 8,055 & 2.6 & 7,452 & 2.4 & 6,445 & 2.1 \\
Rest of the World & 5,300 & 17,640 & 2.5 & 16,111 & 2.3 & 14,112 & 2.0 & 12,889 & 1.8 \\
\hline
\end{tabular}

Note: All GDP values are expressed in purchasing power parity (PPP) terms. Europe includes EU+27, Iceland, Norway, Switzerland, Turkey, Croatia, Albania and the countries of the former Yugoslavia. Rest of Rich Countries includes Canada, Australia, New Zealand and other small islands in the Pacific. Africa includes Africa and the Middle East. Rest of the World includes Russia, other countries in economic transition, Latin America and the rest of Asia. 
Figure A. GDP per capita growth (\%) vs. GDP per capita (US\$ 2005) for 2000-2050 for some regions
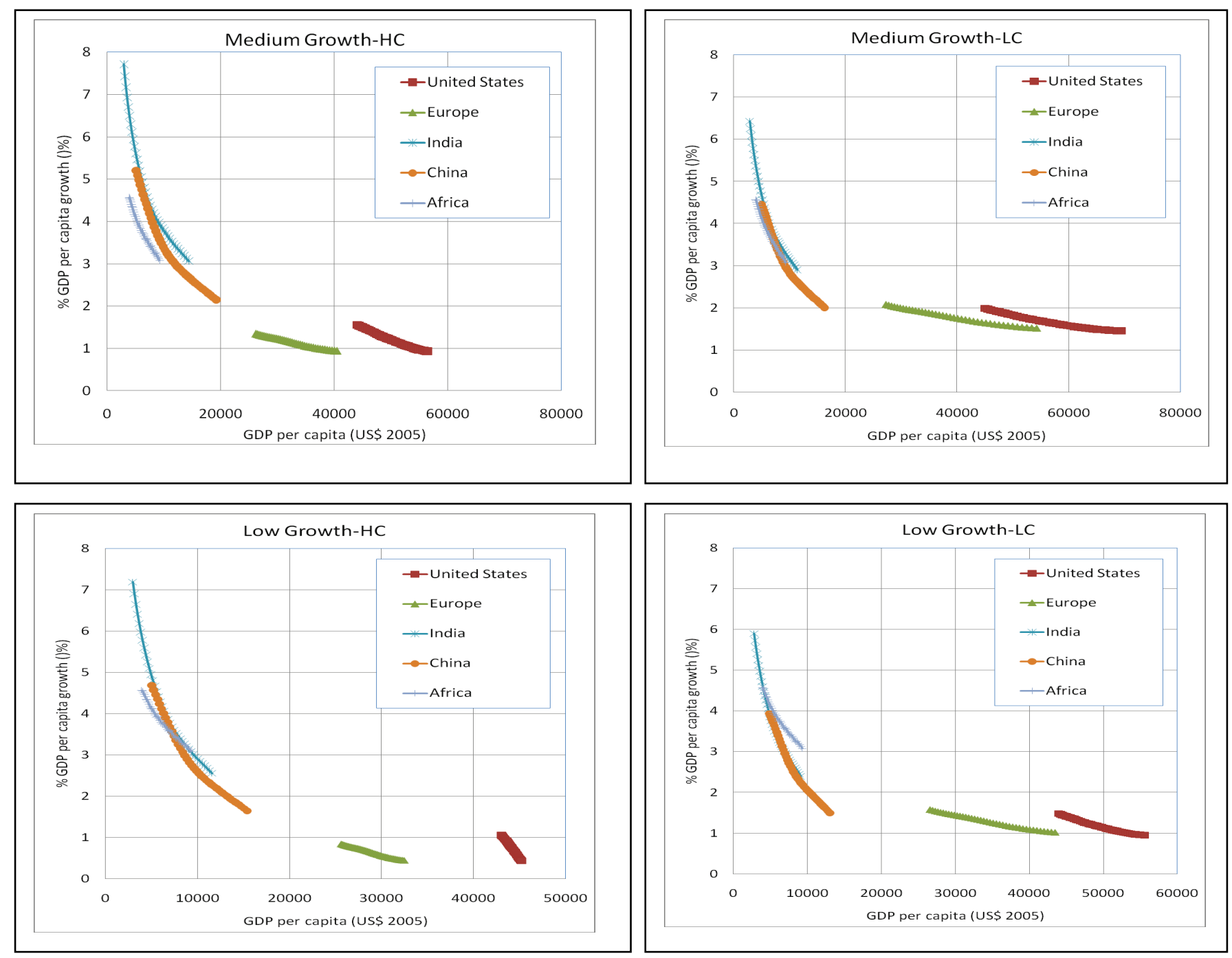
Figure 1. Baseline results for the World and different scenarios
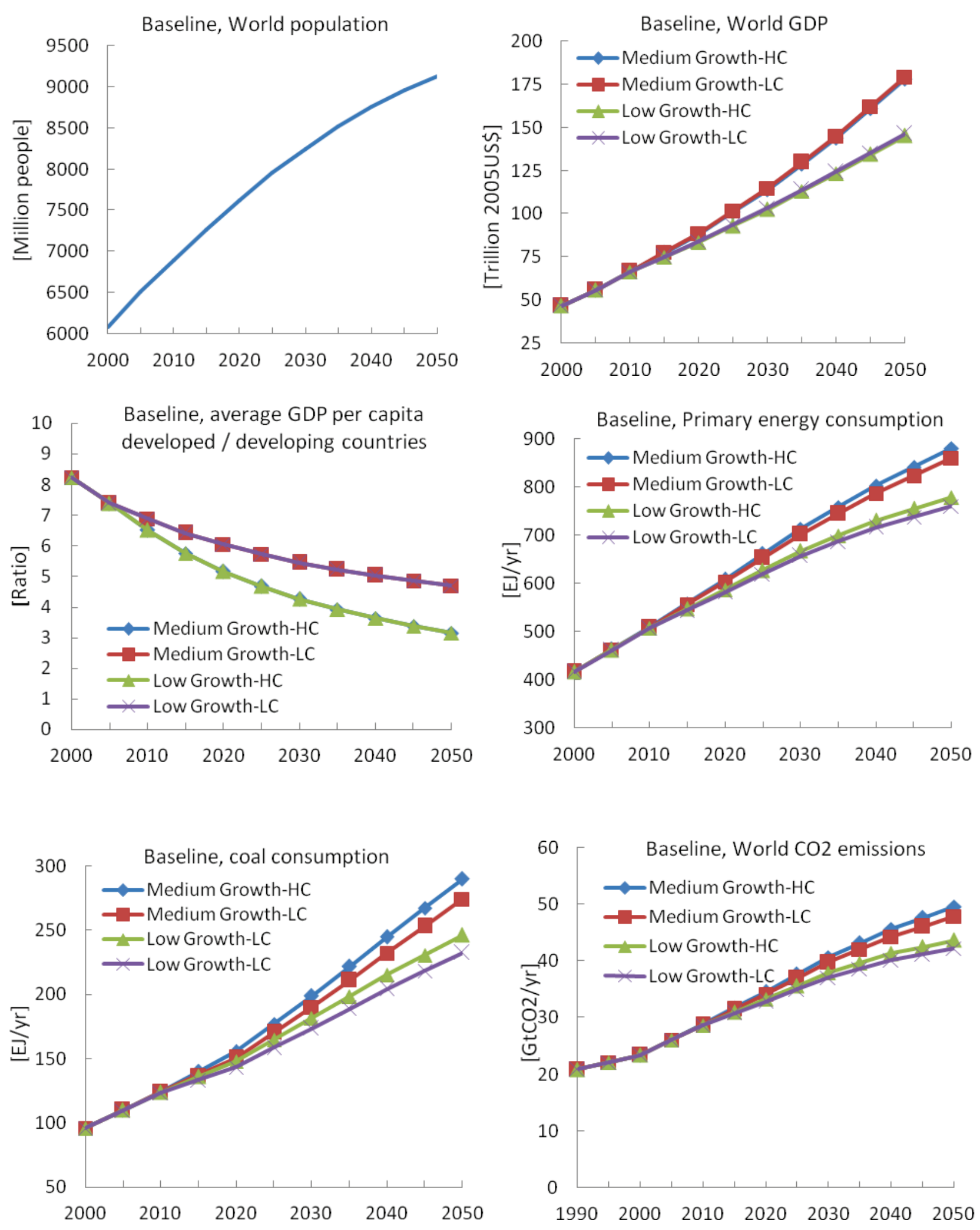
Figure 2. Baseline GDP and CO2 emission distribution in 2050 for different scenarios Baseline, World GDP distribution

- Developed Countries Developing Countries

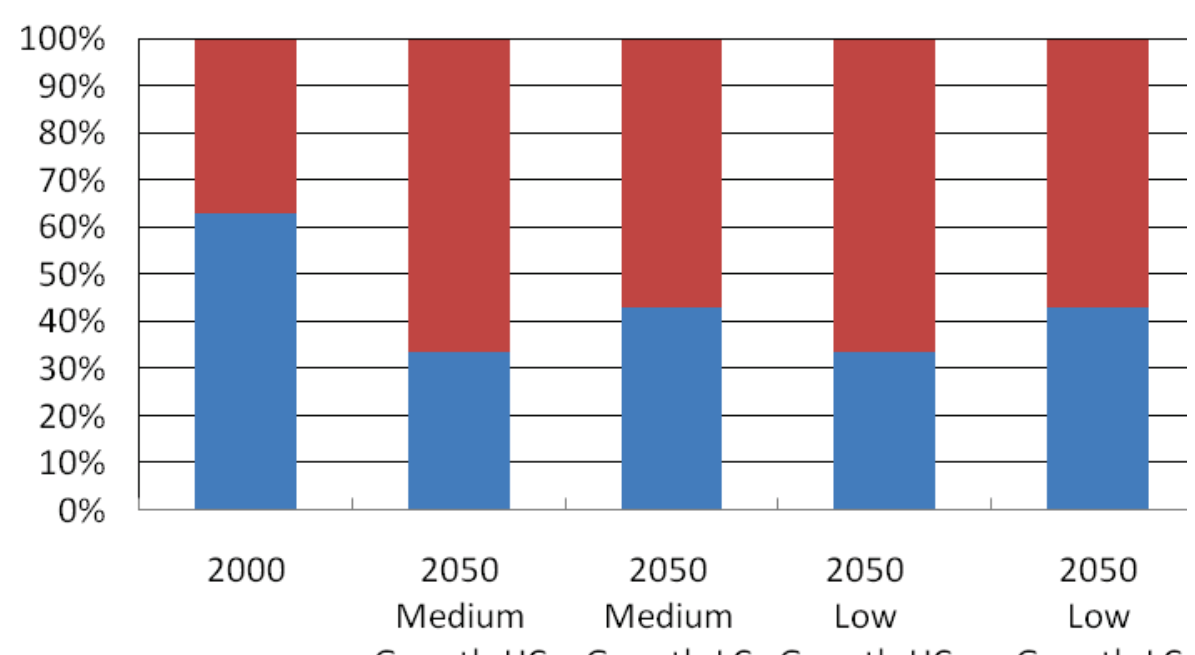

Baseline, World $\mathrm{CO} 2$ emission distribution

- Developed Countries $\quad$ Developing Countries

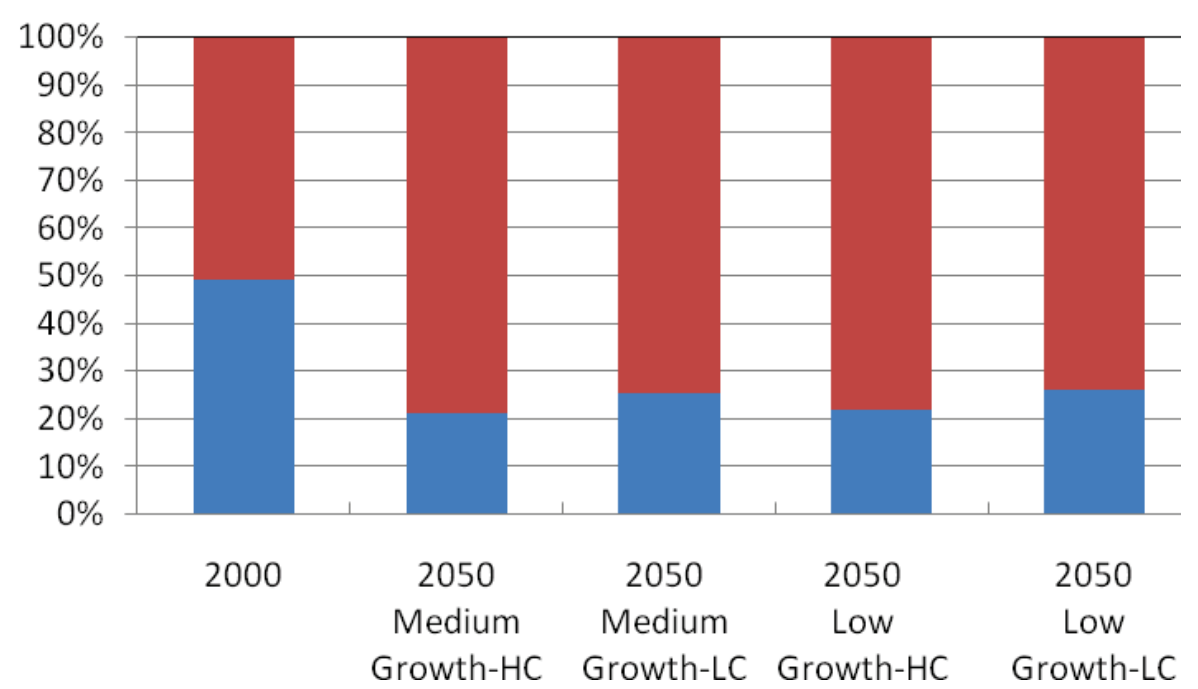


Figure 3. World $\mathrm{CO} 2$ emissions for different scenarios with climate policy

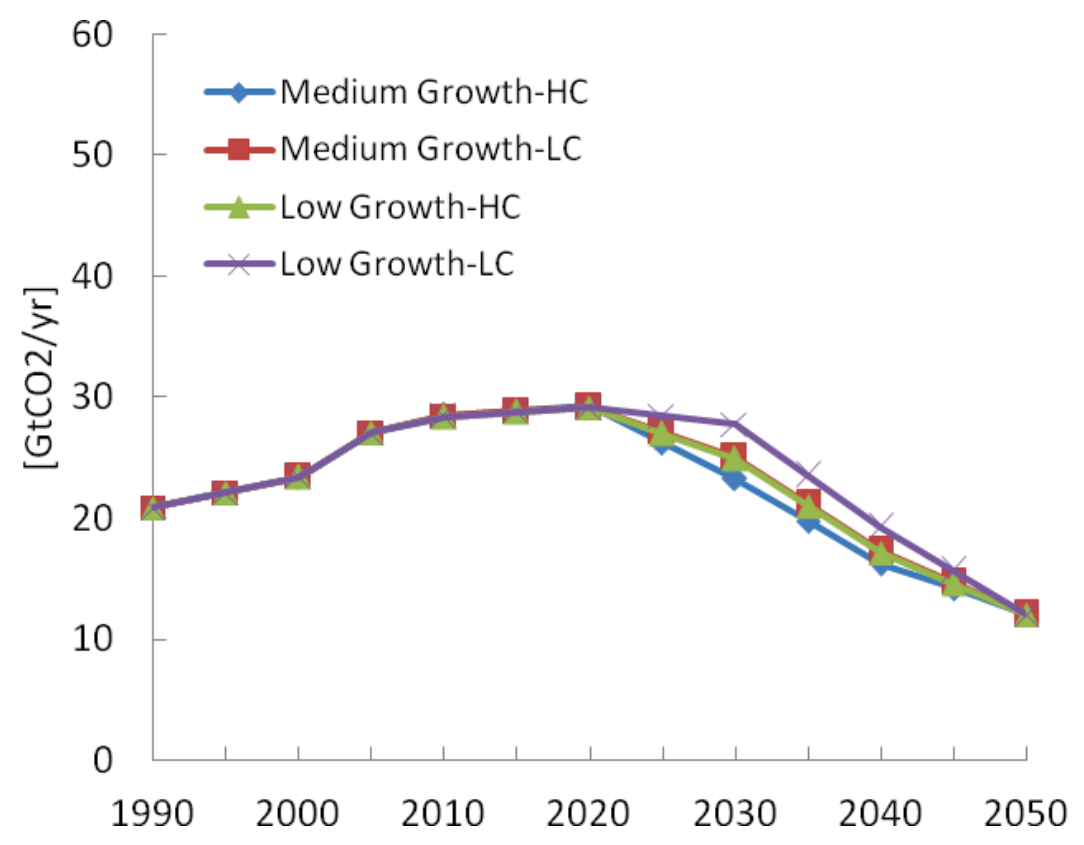

Table 3. $\mathrm{CO} 2$ emissions targets for different areas/regions and a 2 degree stabilisation path (\% from 2000)

\begin{tabular}{lcc}
\hline & 2020 & 2050 \\
\hline EU-27 & $-25 \%$ & $-80 \%$ \\
Rest of Annex B & $-20 \%$ & $-80 \%$ \\
Non-Annex B & $+73 \%$ & $-10 \%$ \\
\hline World & $\mathbf{+ 2 5 \%}$ & $\mathbf{- 5 0 \%}$ \\
\hline
\end{tabular}


Figure 4. Energy results for the World for Medium Growth and High Convergence scenario
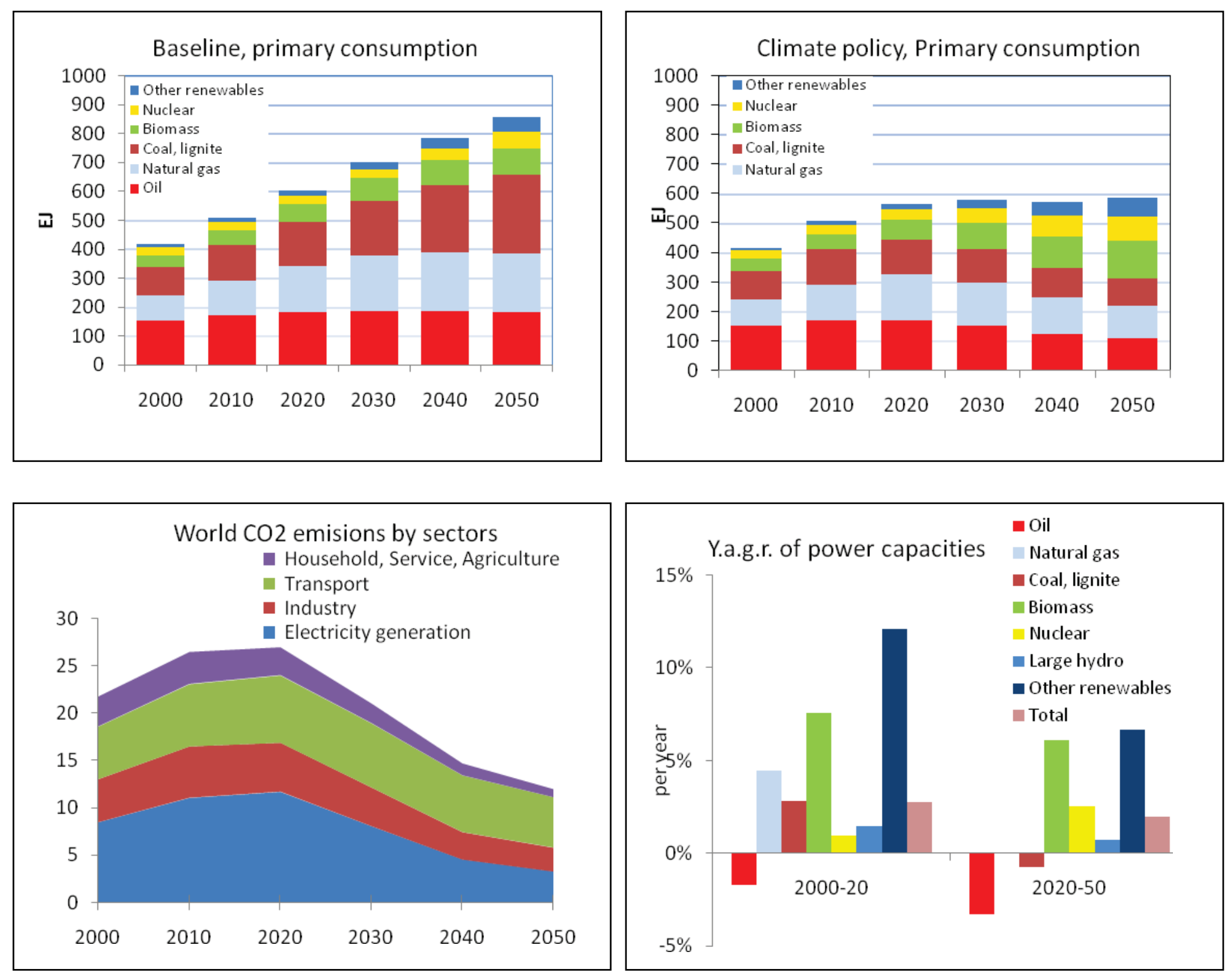
Table 4. General results for Medium Growth and High Convergence scenario

\begin{tabular}{|c|c|c|c|c|c|c|c|}
\hline & & \multirow[b]{2}{*}{2000} & \multicolumn{2}{|c|}{ Baseline } & \multicolumn{2}{|c|}{2 C Stabilisation } & \multirow{2}{*}{$\begin{array}{l}\text { Change }(\%) \\
2050\end{array}$} \\
\hline & & & 2030 & 2050 & 2030 & 2050 & \\
\hline \multicolumn{8}{|l|}{ Overall indicators } \\
\hline Gross internal consumption /GDP & toe/M\$2005 & 214.3 & 150.5 & 118.7 & 122.6 & 79.4 & -33.1 \\
\hline Gross internal consumption /capita & toe/cap & 1.6 & 2.1 & 2.3 & 1.7 & 1.6 & -33.1 \\
\hline Electricity consumption /capita & $\mathrm{MWh} / \mathrm{cap}$ & 2073.3 & 3644.0 & 5178.8 & 3224.8 & 4391.2 & -15.2 \\
\hline $\mathrm{CO} 2$ emissions/capita & $\mathrm{tCO} 2 / \mathrm{cap}$ & 3.8 & 5.0 & 5.5 & 2.8 & 1.3 & -75.5 \\
\hline $\begin{array}{l}\text { \% Renewables in Gross internal } \\
\text { consumption }\end{array}$ & $\%$ & 12.0 & 14.2 & 16.3 & 20.3 & 32.2 & 98.0 \\
\hline Electricity generation & & 21154 & 36105 & 55307 & 31718 & 45652 & -17.5 \\
\hline Thermal, of which : & TWh & 14567 & 27154 & 37899 & 19564 & 22883 & -39.6 \\
\hline Coal, lignite & TWh & 8461 & 15600 & 24533 & 8984 & 8851 & -63.9 \\
\hline of which advanced coal & TWh & 3 & 9286 & 16511 & 7116 & 8284 & -49.8 \\
\hline of which CCS & TWh & 0 & 0 & 0 & 4603 & 7630 & n.a. \\
\hline Gas & TWh & 4203 & 9314 & 10098 & 8213 & 7602 & -24.7 \\
\hline of which combined cycle & TWh & 1936 & 5827 & 6327 & 5440 & 6123 & -3.2 \\
\hline of which CCS & TWh & 0 & 0 & 0 & 2039 & 4972 & n.a. \\
\hline of which cogeneration (industry) & TWh & 406 & 707 & 1153 & 648 & 871 & -24.4 \\
\hline Oil & TWh & 1315 & 703 & 635 & 566 & 258 & -59.3 \\
\hline Biomass & TWh & 182 & 818 & 1313 & 1138 & 5151 & 292.5 \\
\hline Nuclear & TWh & 2796 & 3074 & 5909 & 4855 & 8338 & 41.1 \\
\hline of which new design & TWh & 0 & 1 & 238 & 8 & 576 & 142.4 \\
\hline Hydro (large) & TWh & 3190 & 3666 & 4206 & 3899 & 4389 & 4.3 \\
\hline Hydro (small) & TWh & 167 & 168 & 181 & 257 & 234 & 29.7 \\
\hline Wind & $\mathrm{TWh}$ & 326 & 1131 & 2281 & 1673 & 2459 & 7.8 \\
\hline Solar & TWh & 35 & 771 & 4617 & 1328 & 7108 & 54.0 \\
\hline $\mathrm{CO} 2$ Emissions & $\mathrm{GtCO} 2$ & 0.0 & 0.0 & 49.6 & 23.3 & 12.2 & -75.5 \\
\hline $\mathrm{CO} 2$ Emission Sequestration & $\mathrm{GtCO} 2$ & 0.0 & 0.0 & 0.0 & 4.7 & 9.3 & n.a. \\
\hline
\end{tabular}


Figure 5. Energy Results for the World for Medium Growth and Low Convergence scenario
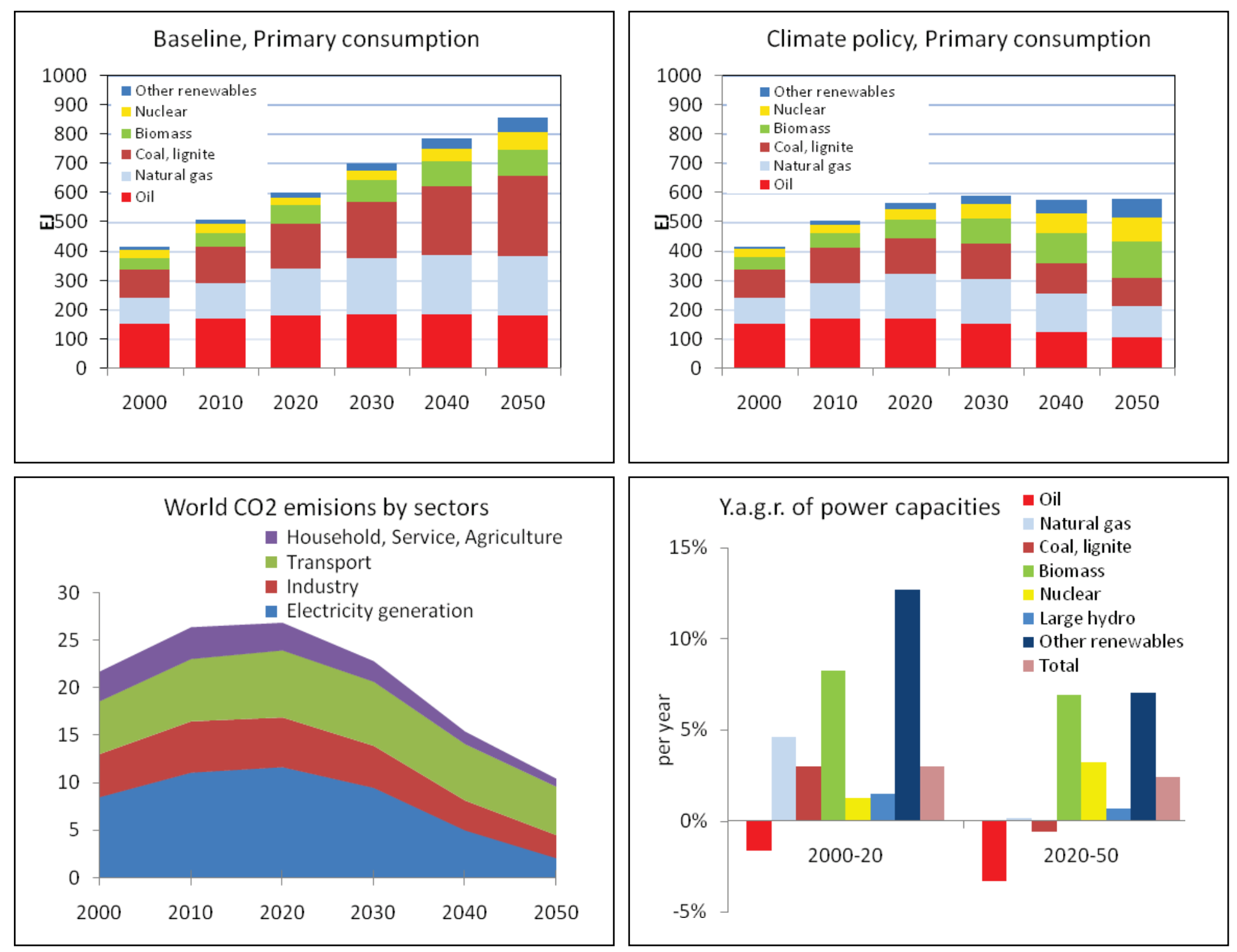
Table 5. General results for Low Growth and Low Convergence scenario

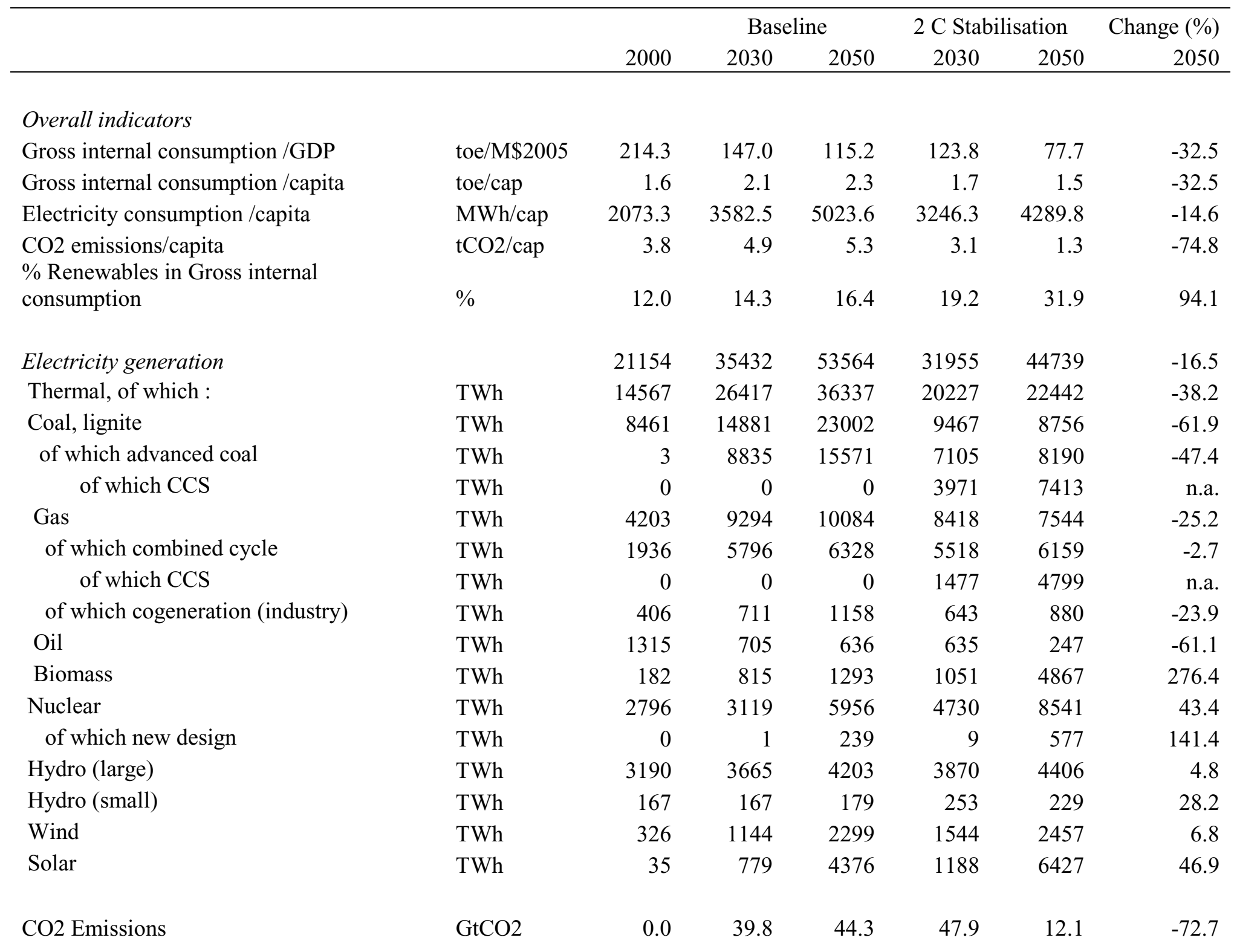


Figure 6. Results for the World for Low Growth and High Convergence
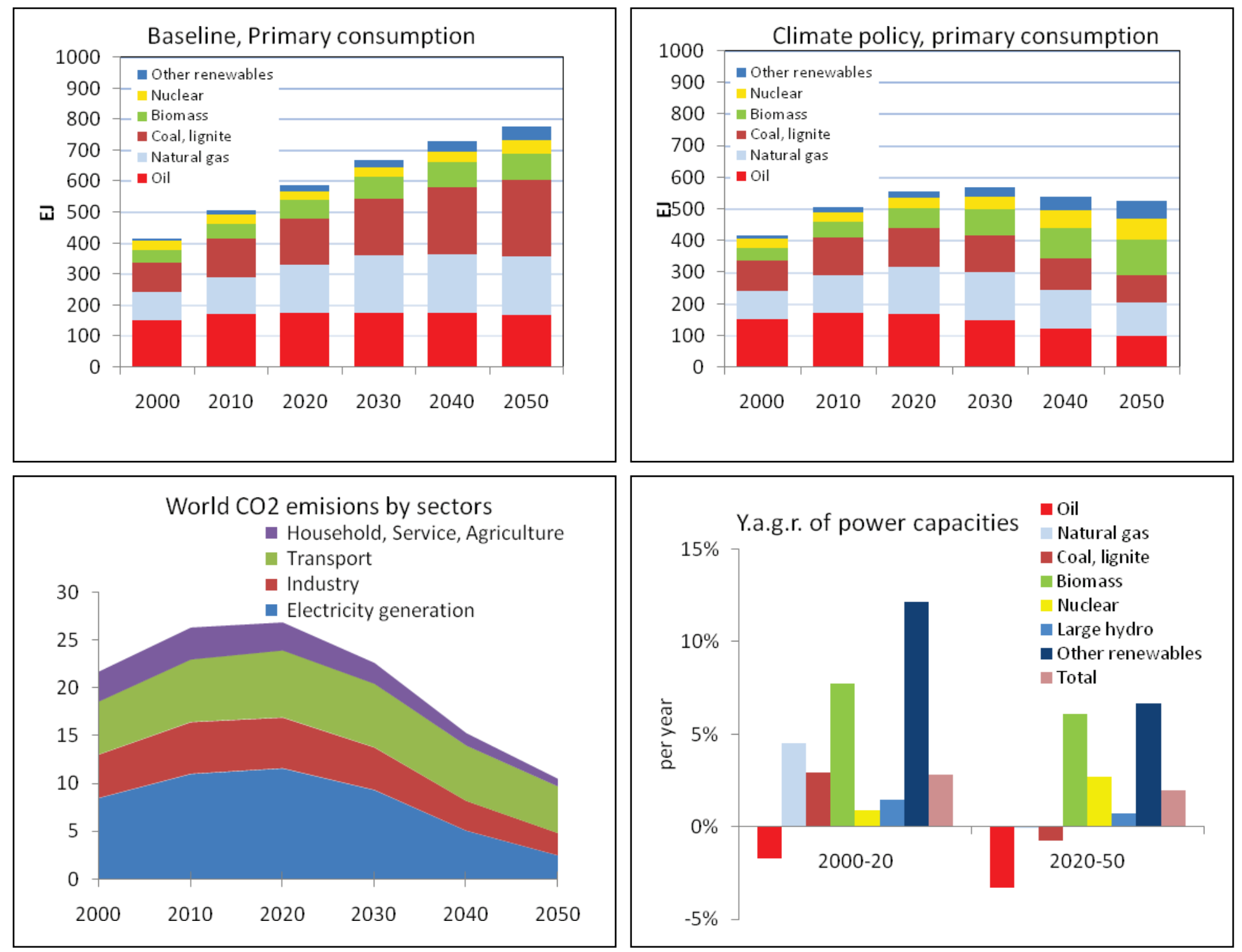
Table 6.General results for Low Growth and High Convergence scenario

\begin{tabular}{|c|c|c|c|c|c|c|c|}
\hline & & \multicolumn{3}{|c|}{ Baseline } & \multicolumn{2}{|c|}{2 C Stabilisation } & \multirow{2}{*}{$\begin{array}{r}\text { Change (\%) } \\
2050 \\
\end{array}$} \\
\hline & & 2000 & 2030 & 2050 & 2030 & 2050 & \\
\hline \multicolumn{8}{|l|}{ Overall indicators } \\
\hline Gross internal consumption /GDP & toe/M\$2005 & 214.3 & 156.4 & 128.7 & 133.4 & 87.1 & -32.3 \\
\hline Gross internal consumption /capita & toe/cap & 1.6 & 2.0 & 2.1 & 1.7 & 1.4 & -32.3 \\
\hline Electricity consumption /capita & $\mathrm{MWh} / \mathrm{cap}$ & 2073.3 & 3339.9 & 4391.0 & 3041.3 & 3739.7 & -14.8 \\
\hline $\mathrm{CO} 2$ emissions/capita & $\mathrm{tCO} 2 / \mathrm{cap}$ & 3.8 & 4.6 & 4.8 & 3.0 & 1.3 & -72.4 \\
\hline$\%$ Renewables in Gross internal consumption & $\%$ & 12.0 & 14.5 & 16.7 & 19.1 & 31.9 & 90.3 \\
\hline Electricity generation & & 21154 & 33100 & 46886 & 30014 & 39082 & -16.6 \\
\hline Thermal, of which: & TWh & 14567 & 24753 & 32443 & 19288 & 20003 & -38.3 \\
\hline Coal, lignite & TWh & 8461 & 14021 & 20330 & 9044 & 8107 & -60.1 \\
\hline of which advanced coal & TWh & 3 & 8228 & 13575 & 6724 & 7540 & -44.5 \\
\hline of which CCS & TWh & 0 & 0 & 0 & 3563 & 6739 & n.a. \\
\hline Gas & TWh & 4203 & 8663 & 9195 & 8043 & 6984 & -24.0 \\
\hline of which combined cycle & TWh & 1936 & 5432 & 5857 & 5259 & 5634 & -3.8 \\
\hline of which CCS & TWh & 0 & 0 & 0 & 1246 & 4226 & n.a. \\
\hline of which cogeneration (industry) & TWh & 406 & 673 & 1092 & 626 & 858 & -21.4 \\
\hline Oil & TWh & 1315 & 658 & 587 & 606 & 240 & -59.1 \\
\hline Biomass & TWh & 182 & 727 & 1090 & 955 & 3673 & 236.9 \\
\hline Nuclear & TWh & 2796 & 2728 & 4408 & 4079 & 6580 & 49.2 \\
\hline of which new design & TWh & 0 & 1 & 128 & 6 & 375 & 192.5 \\
\hline Hydro (large) & TWh & 3190 & 3660 & 4192 & 3859 & 4414 & 5.3 \\
\hline Hydro (small) & TWh & 167 & 166 & 176 & 247 & 235 & 33.4 \\
\hline Wind & TWh & 326 & 987 & 1781 & 1386 & 2025 & 13.7 \\
\hline Solar & TWh & 35 & 664 & 3680 & 1014 & 5600 & 52.2 \\
\hline $\mathrm{CO} 2$ Emissions & $\mathrm{GtCO} 2$ & 0.0 & 37.9 & 43.7 & 24.9 & 12.1 & -72.4 \\
\hline
\end{tabular}


Figure 7. Results for the World for Low Growth and Low Convergence
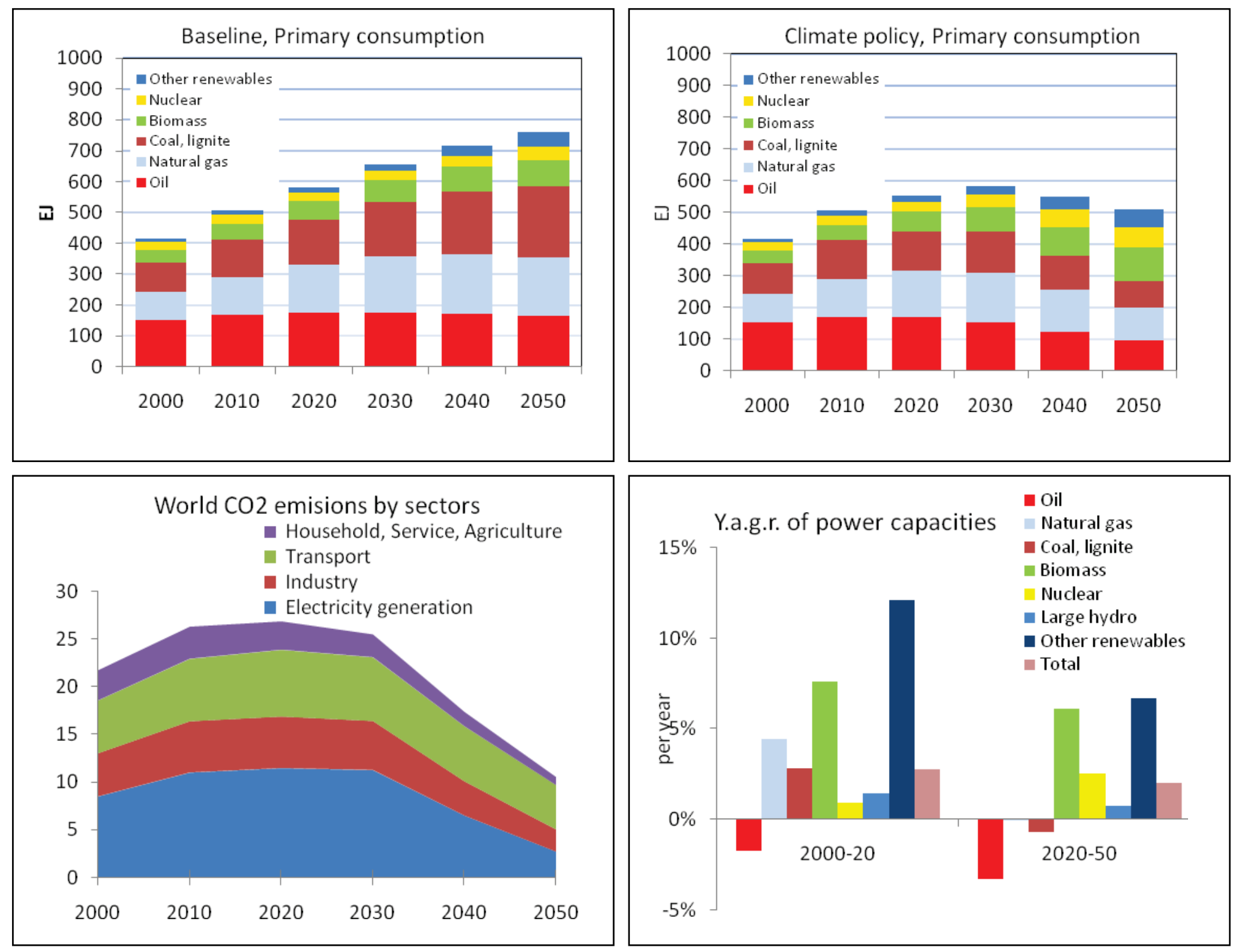
Table 7. General results for Low Growth and Low Convergence scenario

\begin{tabular}{|c|c|c|c|c|c|c|c|}
\hline & & \multicolumn{3}{|c|}{ Baseline } & \multicolumn{2}{|c|}{2 C Stabilisation } & \multirow{2}{*}{$\begin{array}{r}\text { Change }(\%) \\
2050\end{array}$} \\
\hline & & 2000 & 2030 & 2050 & 2030 & 2050 & \\
\hline \multicolumn{8}{|l|}{ Overall indicators } \\
\hline Gross internal consumption /GDP & toe/M\$2005 & 214.3 & 152.8 & 124.8 & 135.6 & 84.1 & -32.7 \\
\hline Gross internal consumption / capita & toe/cap & 1.6 & 1.9 & 2.0 & 1.7 & 1.4 & -32.7 \\
\hline Electricity consumption /capita & MWh/cap & 2073.3 & 3284.7 & 4258.0 & 3062.4 & 3611.0 & -15.2 \\
\hline $\mathrm{CO} 2$ emissions/capita & $\mathrm{tCO} 2 / \mathrm{cap}$ & 3.8 & 4.5 & 4.7 & 3.4 & 1.3 & -71.4 \\
\hline$\%$ Renewables in Gross internal consumption & $\%$ & 12.0 & 14.6 & 16.9 & 17.8 & 32.0 & 89.5 \\
\hline Electricity generation & & 21154 & 32494 & 45404 & 30214 & 37784 & -16.8 \\
\hline Thermal, of which : & TWh & 14567 & 24107 & 31082 & 20079 & 19124 & -38.5 \\
\hline Coal, lignite & TWh & 8461 & 13372 & 19055 & 9838 & 7523 & -60.5 \\
\hline of which advanced coal & TWh & 3 & 7805 & 12795 & 6648 & 6950 & -45.7 \\
\hline of which CCS & TWh & 0 & 0 & 0 & 2126 & 5996 & n.a. \\
\hline Gas & TWh & 4203 & 8666 & 9132 & 8102 & 6808 & -25.4 \\
\hline of which combined cycle & TWh & 1936 & 5406 & 5816 & 5270 & 5511 & -5.2 \\
\hline of which CCS & TWh & 0 & 0 & 0 & 814 & 3854 & n.a. \\
\hline of which cogeneration (industry) & TWh & 406 & 676 & 1091 & 623 & 865 & -20.7 \\
\hline Oil & TWh & 1315 & 658 & 590 & 668 & 237 & -59.8 \\
\hline Biomass & TWh & 182 & 724 & 1070 & 835 & 3552 & 232.1 \\
\hline Nuclear & TWh & 2796 & 2746 & 4449 & 3797 & 6289 & 41.3 \\
\hline of which new design & TWh & 0 & 1 & 132 & 6 & 359 & 172.0 \\
\hline Hydro (large) & TWh & 3190 & 3659 & 4190 & 3813 & 4439 & 6.0 \\
\hline Hydro (small) & TWh & 167 & 164 & 174 & 239 & 235 & 34.8 \\
\hline Wind & TWh & 326 & 996 & 1797 & 1190 & 1934 & 7.6 \\
\hline Solar & TWh & 35 & 679 & 3507 & 953 & 5540 & 57.9 \\
\hline CO2 Emissions & $\mathrm{GtCO} 2$ & 0.0 & 37.1 & 42.2 & 27.8 & 12.1 & -71.4 \\
\hline CO2 Emission Sequestration & $\mathrm{GtCO} 2$ & 0.0 & 0.0 & 0.0 & 2.3 & 7.1 & n.a. \\
\hline
\end{tabular}


Figure 8. Impact of climate policy on capacities for the main power-generating technologies in the different scenarios
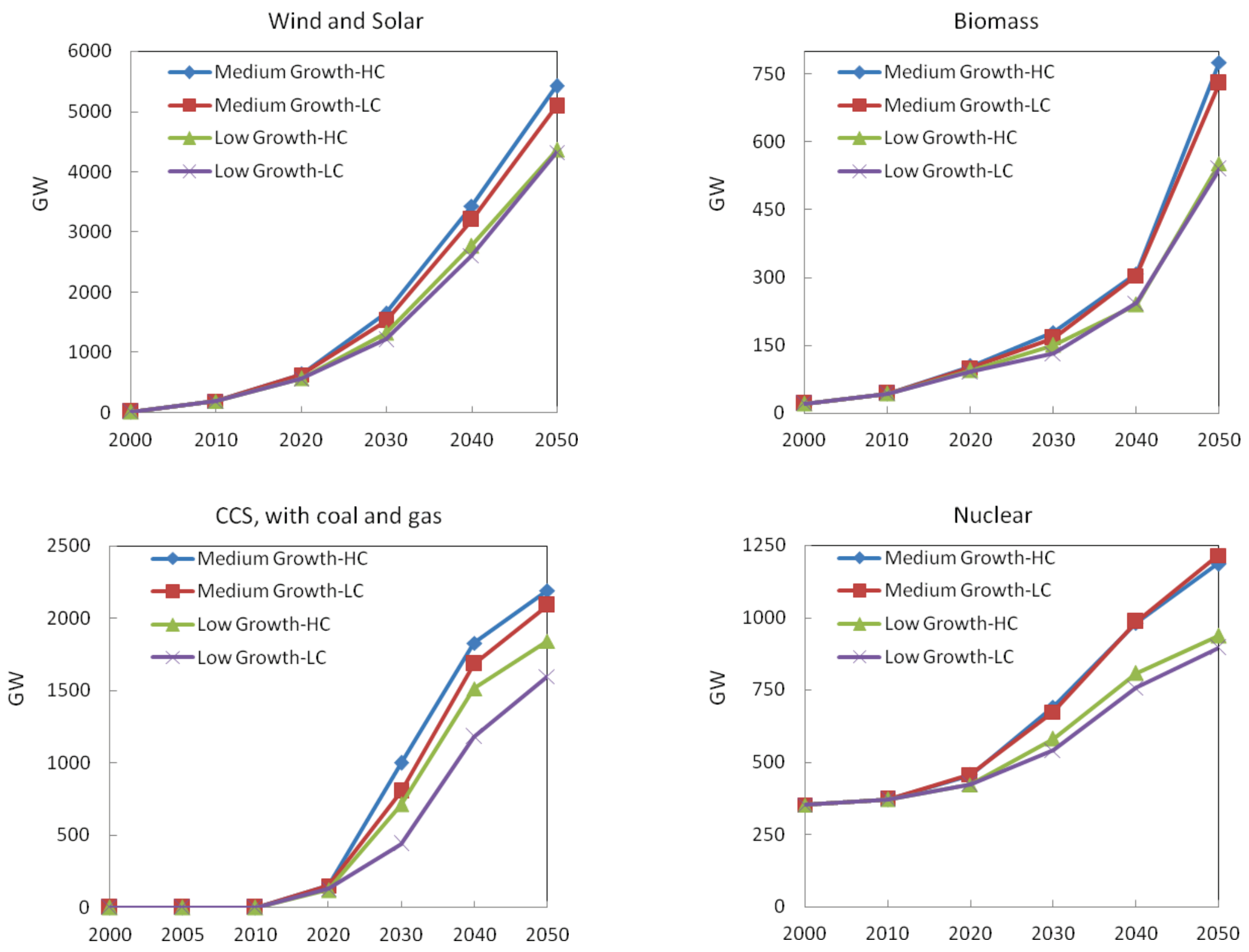
Figure 9. Carbon values $(€ / \mathrm{tCO} 2)$ for different scenarios and regions
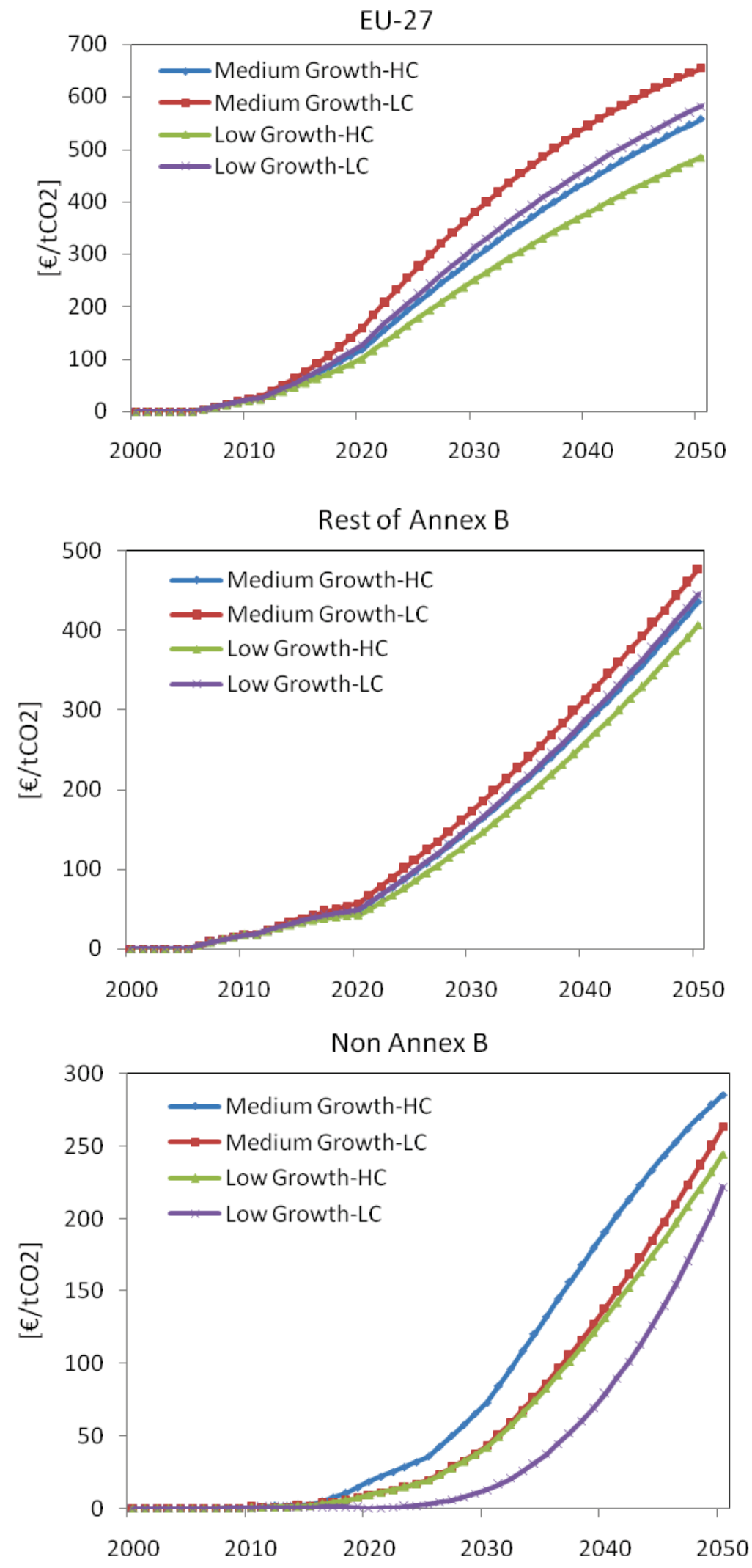
Figure 10. Mitigation cost (Billions US\$2005) for the world and different scenarios

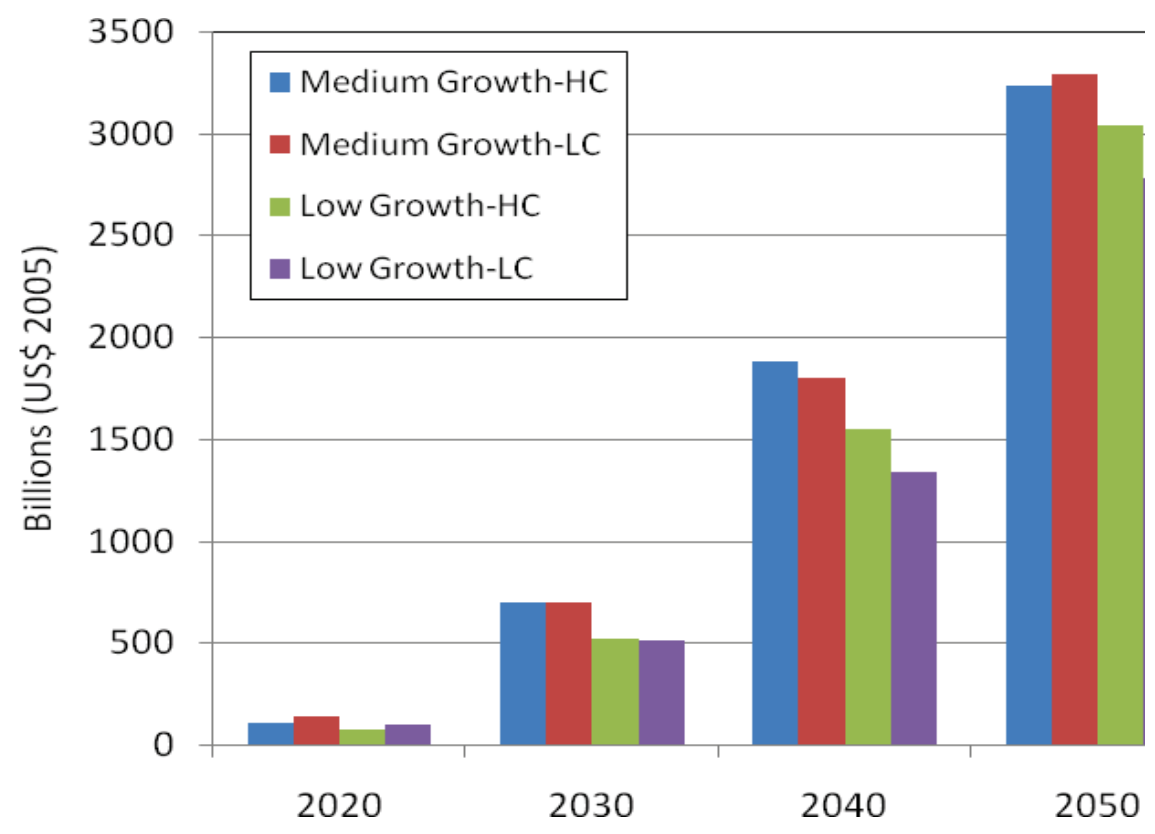

Table 8. Economic impact (\%/GDP) for the world and different scenarios

\begin{tabular}{lrrrr}
\hline & 2020 & 2030 & 2040 & 2050 \\
\hline Medium Growth-HC & 0.12 & 0.61 & 1.31 & 1.81 \\
Medium Growth-LC & 0.16 & 0.61 & 1.24 & 1.83 \\
Low Growth-HC & 0.09 & 0.50 & 1.25 & 2.09 \\
Low Growth-LC & 0.12 & 0.49 & 1.07 & 1.90 \\
\hline
\end{tabular}


Figure 11. Regional mitigation cost (Billions US\$ 2005) for different scenarios in 2050

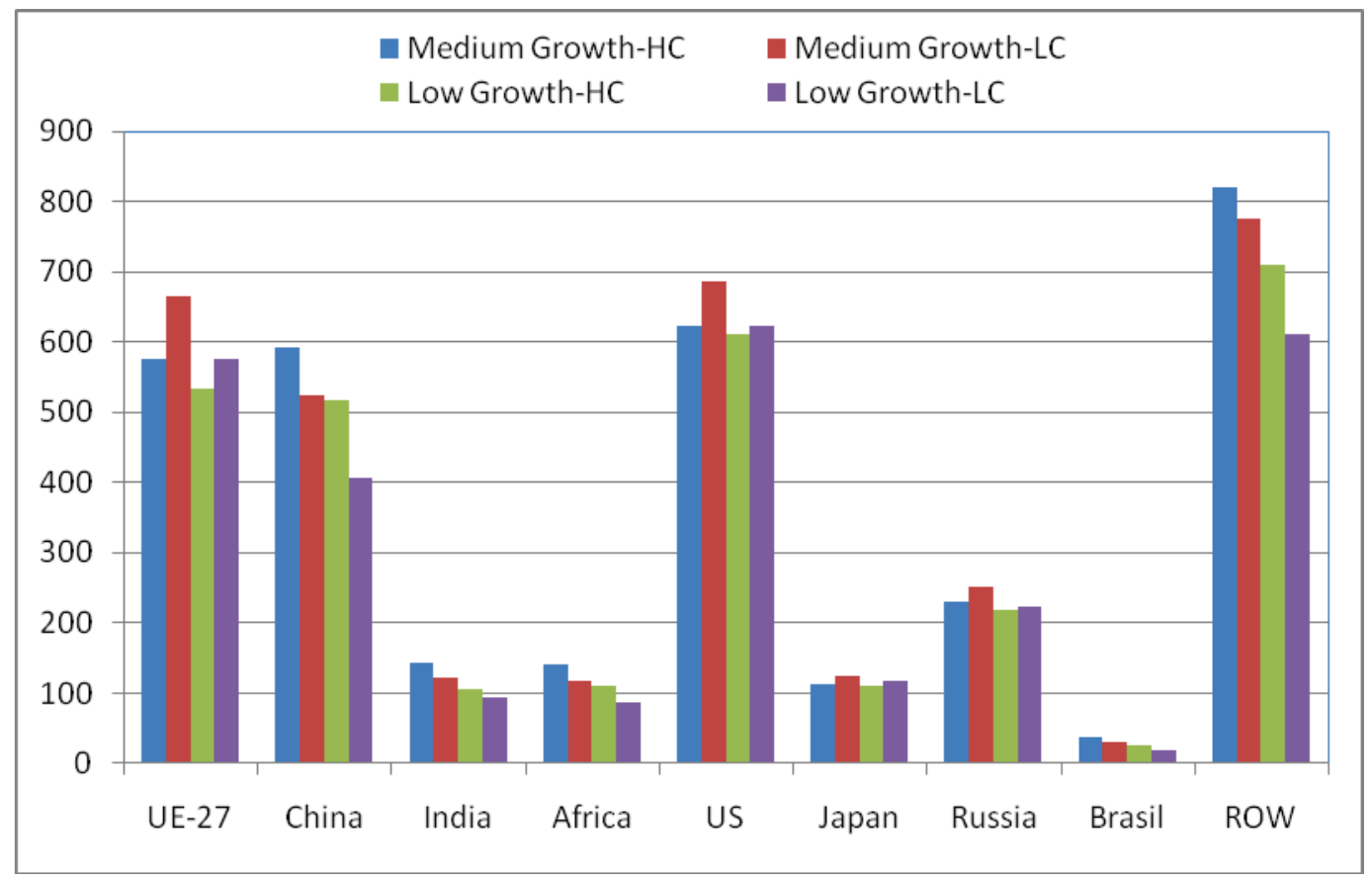


Figure 12. Regional economic impact (\%/GDP) for the world and different scenarios 2000-2050
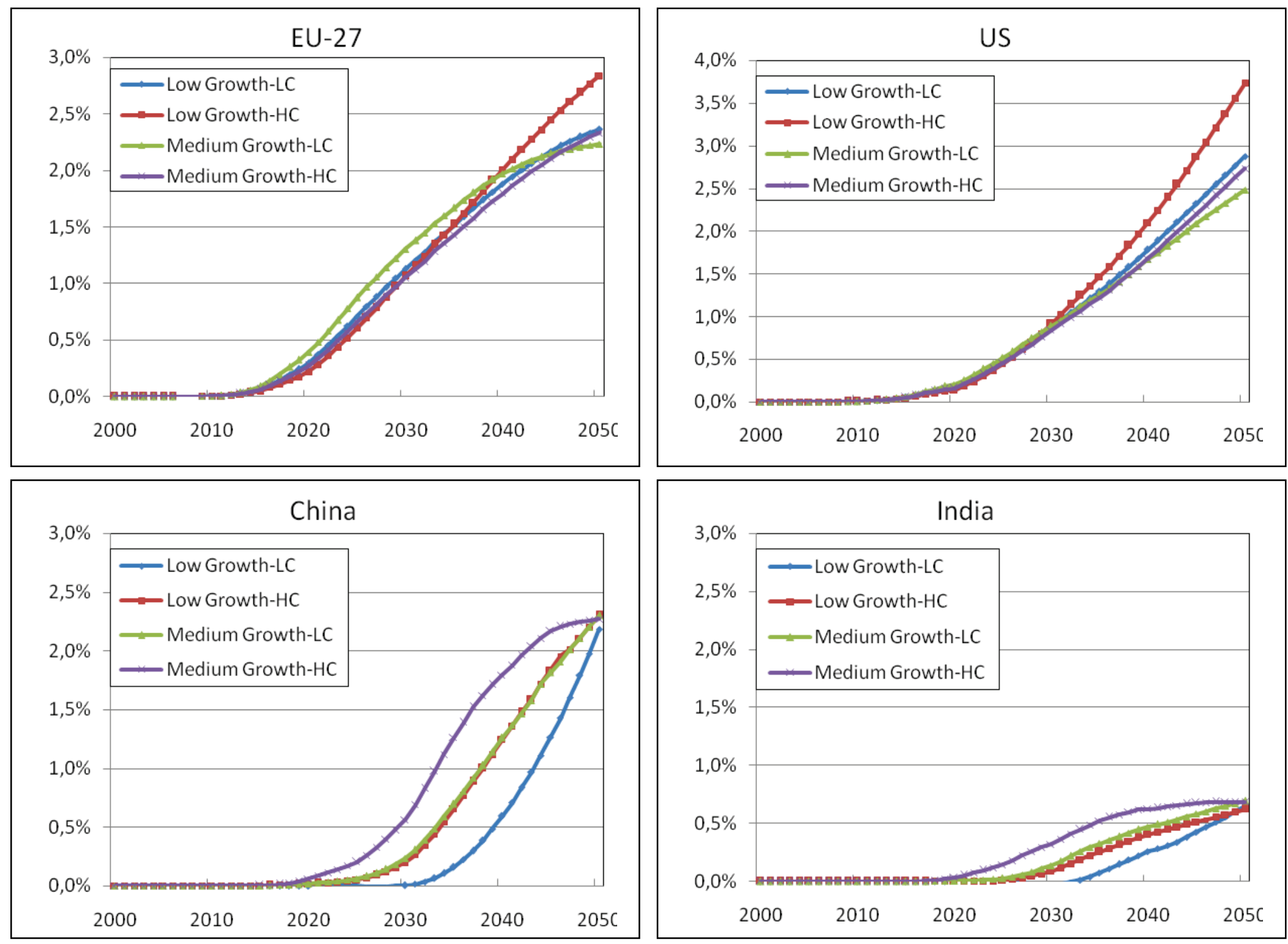